ELOISA APARECIDA GUEDES

\title{
VALOR COMPARATIVO DO TESTE TUBERCULINICO REPETIDO DEPOIS DE 72 HORAS
}

\author{
Dissertaçáo de Mestrado apre \\ sentada a Faculdade de Saúde \\ Pública da Universidade de \\ São Paulo, Departamento de \\ Epidemiologia para obtenção \\ do título de Mestre em Saúde \\ pública. \\ orientador:Prof. Dr. Roberto Brólio
}

SÃO PAULO

1978

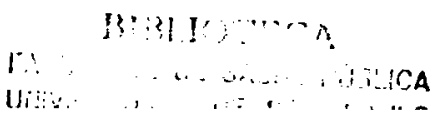


$\bar{\lambda}$ minha família 
Ao Prof. Dr. Roberto irölio pela orientaçäo e interesse à realização deste trabalho.

Ao Prof. Dr. Walter Mauricio Correa pela amizade e incentivo.

A Dra. Maria Iacyra de Campos Nogueira pelo constante estimulo à nussa formaçäo profissional.

A professora Nilza Nunes da Silva pela orientação, e acampanhamento da parte estatistica.

$\bar{A}$ colega liétina Lucia Laudari pela valiosa colaboração e am izade.

Ís colegas Malvina Ramos Netto, Vilma Yachado Queiroz, Dora lice Souza Franco de Andrade, Emike Yoshikawa Egry e Rosa Maria lodoy Serpa da Fonseca, pela amizade e estimulo recebido.

$\bar{A}$ direção, funcionários e crianças da Fundação do Bem-Estar do Menor de Säo paulo (FFBEM) que favoreceram a realizasão deste trabalho.

As bibliotecārias da Escola de Enfermagem da Universidade de Säo paulo, pela atenção e disponibilidade.

$\bar{A}$ todos que direta ou indiretamente colaboraram na realização deste trabalho. 


\section{I $N$ N L I I C C E}

PAG.

INDICE DE FIGURAS $\ldots \ldots \ldots \ldots \ldots \ldots \ldots \ldots \ldots \ldots$ V

INDICE

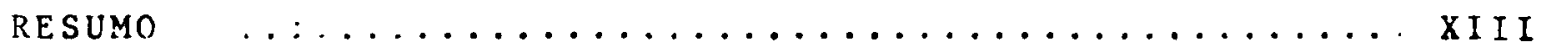

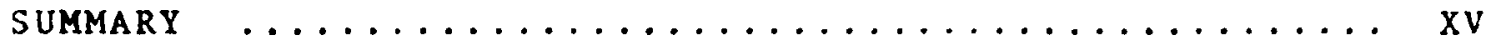

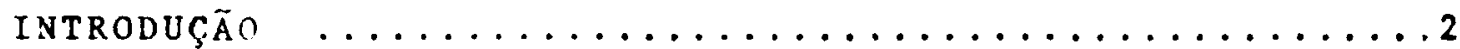

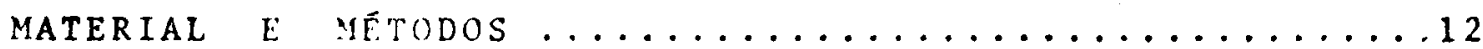

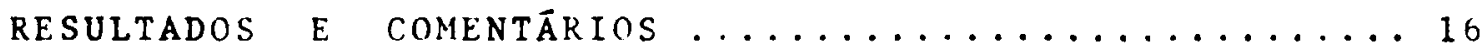

- 1a. aplicação do teste tuberculínico ............ 16

- 2a. aplicação do teste tuberculínico ............ 20

- análise comparativa da la. e 2a. aplicações ........23

-influência das variáveis:

- tempos de leitura ....................

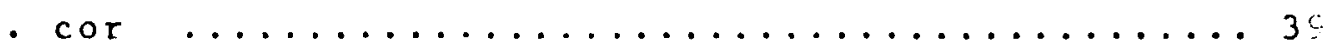

- vacinação BCG-id ..................

- local de aplicação do 2 g teste............ 52

- discussão das hipöteses ................. 56

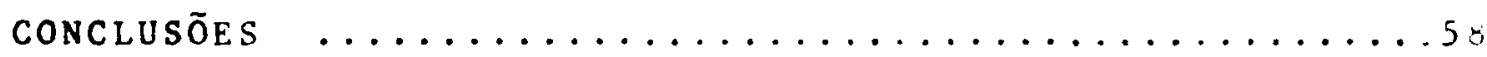

REFERENCIAS BIBLIOGRÁFICAS $\ldots \ldots \ldots \ldots \ldots \ldots \ldots \ldots \ldots \ldots \ldots \ldots \ldots \ldots \ldots$ 
FIGURA 1 - bistribuição dos resultados das medidas em mm, da la. aplicação da prova tuberculínica, segundo os tempos de leitura, em pessoas de 5 a 15 anos de idade, per tencentes a tres Unidades da FEBEM.São Paulo, 1977 .

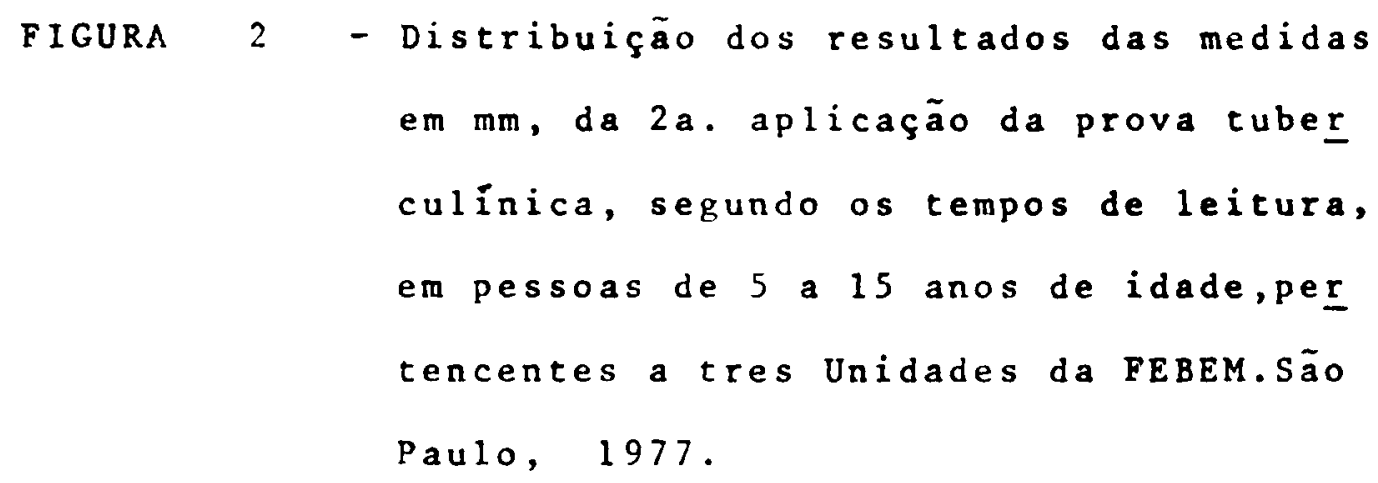
em $\mathrm{mm}$, da $2 \mathrm{a}$. aplicação da prova tuber culinica, segundo os tempos de leitura, em pessoas de 5 a 15 anos de idade,per tencentes a tres Unidades da FEBEM.São Paulo, 1977 .

FIGURA 3 - Distribuição dos resultados das medidas em $\mathrm{mm}$, das provas tuberculínicas, segun do as aplicaçóes e leituras de 24 horas, em pessoas de 5 a 15 anos de idade, pertencentes a tres Unidades da FE BEM. São Paulo, 1977 .

FIGURA 4 - Distribuição dos resultados das medidas em mm, das provas tuberculínicas, segun do as aplicações e leituras de 48 horas, em pessoas de 5 a 15 anos de idade, per tencentes a tres Unidades da FEBEM.São 


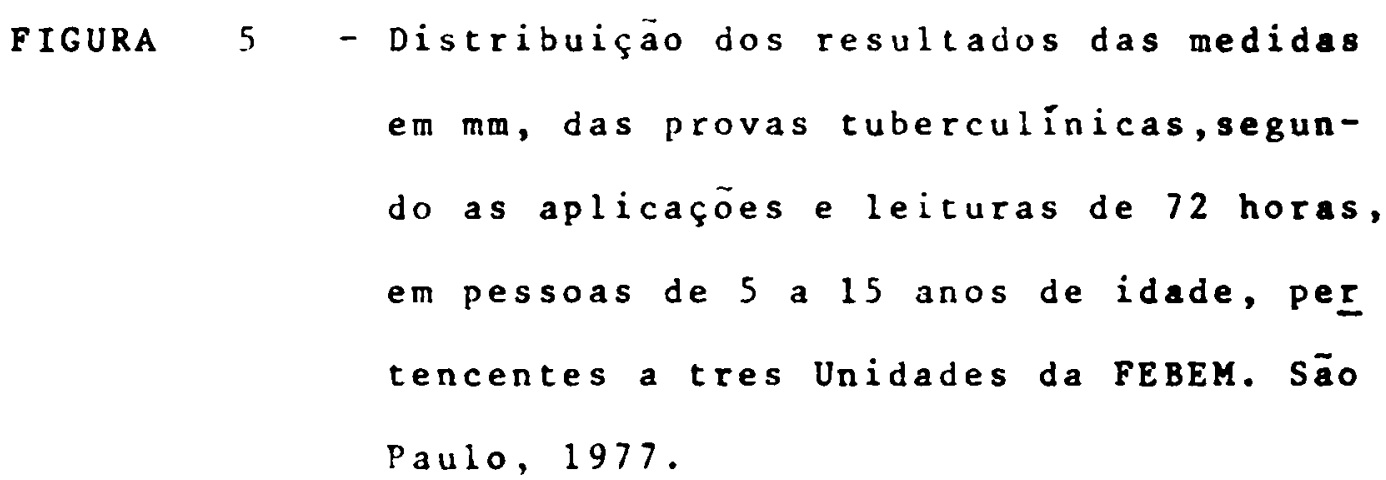


aplicação do teste tuberculínico,feito de pois de 72 horas, em pessoas de 5 a 15 a nos de idade, pertencentes a tres Unidades da FEBEM. São paulo, 1977.

TABELA 6 - Distribuição dos resultados da segunda a plicaçào do teste tuberculínico, segundo idade e classificação qualitativa,em pes soas de 5 a 15 anos de idade, pertencentes a tres Unidades da FEBEM.São Paulo 1977

TABELA 7 - Distribuição dos resultados da la.e 2 a.a plicações do teste tuberculínico, em pes soas de 5 a 15 anos de idade, pertencentes a tres Unidades da FEBEM.São Paulo, 1977 .

TABEla 8 - Comparaçäo dos resultados da la. e 2 a. a plicaçries do teste tuberculinico, em pessoas de 5 a 15 anos de idade, pertencentes a tres Unidades da FEBEM.São Paulo, 1977.

TABELA G - Distribuição dos resultados das medidas, em $\mathrm{mm}$, das médias, desvios padröes e coeficientes de variaçào, das provas tuberculínicas, segundo as aplicaçóes e os tem pos de leitura, em pessoas de 5 a 15 anos 
de idade, pertencentes a tres Unidades da FEBEM. São Paulo, 1977.

TABELA 10- Distribuição dos resultados segundo a clas sificação qualitativa da la. e 2a. aplicaçôes do teste tuberculínico, e os tempos de leitura, em pessoas de 5 a 15 anos de ida $=$ de, pertencentes a tres Unidades da FEBEM. Säo Paulo, 1977 .

TABELA 11-Distribuição dos resultados da la. aplicaçāo do teste tuberculínico, segundo a cor e a classificação qualitativa,em pessoas de 5 a 15 anos de idade, pertencentes a tres Unidades da FEBEM. São Pauio, 1977.

TABELA 12-Distribuição dos resultados da 2 a aplica ção do teste tuberculínico,segundo a cor e a classificação qualitativa, em pessoas de 5 a 15 anos de idade, pertencentes a tres Unidades da FEBEM. São Paulo, 1977.

TABELA 13 -Distribuição dos resultados da la. e $2 a \cdot a$ plicaçöes do teste tuberculínico,em pesso as de 5 a 15 anos de idade, brancis, pertencentes a tres unidades da FEBLi. säo Paulo, 1977 .

TABELA 14 -Distribuição dos resultados da la. e za. 
plicaçöes do teste tuberculínico, em pessoas de 5 a 15 anos de idade, näo brancas, per tencentes a tres Unidades da FEBEM.São Paulo, 1977 .

TABEla 15-Distribuiçäo dos resultados da la. aplicação do teste tuberculínico,em pessoas de 5 a 15 anos de idade, pertencentes a tres unidades da FEBEM, vacinadas e não vacinadas anterior mente com BCG-id.säo paulo, 1977.

TABELA 16-Distribuição dos resultados da $2 a$ aplicação do teste tuberculínico, em pessoas de 5 a 15 anos de idade, pertencentes a tres Unidades da FEBEM, vacinadas e não vacinadas anterior mente com BCG-id. São Paulo, 1977.

TABELA 17-Distribuiçäo dos resultados da 1 a. e $2 a$ a plicaçöes do teste tuberculínico, em pesso=as de 5 a 15 anos de idade, pertencentes a tres Unidades da FEBEM, não vacinadas anteriormente com BCG-id. São Paulo, 1977.

TABELA 18-Distribuiçäo dos resultados da la. e $2 a$ a plicaçöes do teste tuberculńico, em pessoas de 5 a 15 anos de idade, pertencentes a tres Unidades da FEBEM, vacinadas anterior mente com BCG-id. São Paulo, 1977. 
TABELA 19-Distribuição dos resultados da $2 a$. prova tuberculínica, segundo o local de aplicação, em pessoas de 5 a 15 anos de idade, pertencentes a tres Unidades da FEBEM.São Paulo, 1977 . 
R E S S L C M 
Foi feito o estudo compa rativo co teste tuberculínico com PPD,Rt-23,2UT, repetido de pois de 72 horas, com leituras de 24,48 e 72 horas após cada aplicação, em 415 pessoas de 5 a 15 anos de idade, de ambos os sexos, vacinadas e não vacinadas anteriormente com BCG-ittradērmico, pertencentes a tres Unidades da Fundação do Bem-Es tar do Menor (FEBEM), Säo Pau10,1977 . Os resultados valori zam a 2a.aplicação do teste tü berculínico,e as leituras após 72 horas de cada aplicação. A 2a.aplicação mostrou maior per centual de reatores, detectando com maior probabilidade, os fal sos negativos da la. aplicação do teste tuberculínico. 



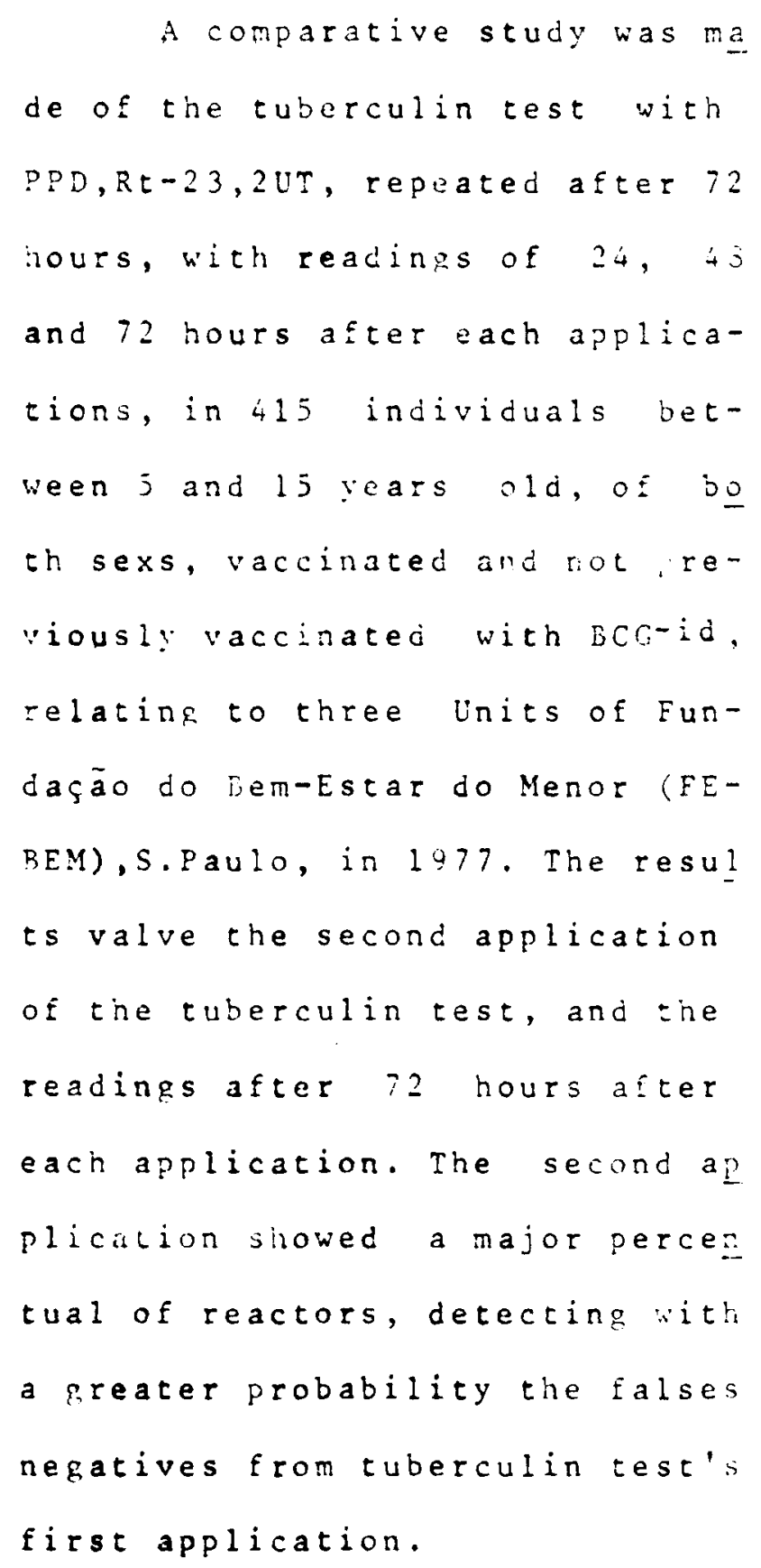




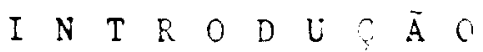


o presente trabalio tem por objetivo estudar o comportamento da reatividade tuberculínica, em pessos de 5 a 15 anos de idade, através da aplicação do teste tuberculí nico padronizado OMS (PPD, Rt-23, 2 UT), e por aplicação rẹ petida do mesmo após 72 horas; comparar os resultados dala. e da 2a. aplicações do teste, nas leituras de 26,48 e 72 horas; verificar se hà ou não alterações nas leituras das duas aplicaçôes e se as reações foram causadas por trauma tismo local ou efeito da sensibilização alérgica anterior (booster).

A prova tuberculínica oferece uma grande vantagem nos programas de luta contra a tuberculose, especialmen te nos países em desenvolvimento, por ser um meio eficaze economico para detectar as pessoas infectadas pelo bacilo da tuberculose, numa determinada população.

A Comissão de Peritos da Organizaçáo Mundia da Saüde (OMS) 16 (1964), valoriza o indice de prevalénc: infecção tuberculosa entre os três indices mais importantes para avaliar a magnitude do problema e Eixar a orientação que se deve dar aos programas de luta anti-tuberculose.

Esses indices são os de prevalência da infecção especifica, de prevalência de doentes bacilíferos e de prevalência de indivíduos com imagens radiológicas ativas. 
berculínica realizada periodicamente permite deduzir a inci dência anual e avaliar a tendência evolutiva da infecção nu ma coletividade. Ela é igualmente útil no estudo clínico de casos, oferecendo subsidios importantes para a valorização dos meios de diagnóstico da tuberculose na infância.

Qualitativamente, quando positiva, nas primeiras idades, evidencia a existência de uma primo-infeção e, quando se conhecem as reações anteriores, seguidamente nega tivas, e que se tornaram positivas (viragem tuberculínica), permite detectar a infecção recente.

Embora possa apresentar reações cruzadas para as infecções por micobactérias atípicas e pelo BCG, a exis tência de uma reação significativa, en crianças não vacinadas anteriormente, é praticamente específica para a tubercu lose, possibilitando estabelecer medidas profiláticas e terapêticas de valor inestimável. Quando negativa, exclui a possibilidade de se tratar de infeção tuberculosa.

Quantitativamente, em pessoas de pouca idade reatores fortes, com enduração acima de $10 \mathrm{~mm}$ de diâmetro, a prova tuberculínica orienta a indicação da quimioprofilaxia ou da quimioterapia específicas.

E pois, no campo da clínica e da epidemiologia que o tuberculino-diagnóstico tem a sua indicação, sendo o único meio através do qual se pode apurar o grau de infec ção tuberculosa no indivíduo e a extensão da mesma na população. Respeitados os casos de vacinação pelo BCG intradér- 
mico, as reações positivas indicam os infectados e as negativas os não infectados pelo bacilo de Kock.

Os estudos realizados com a aplicação da prova tuberculínica, comprovam e reconhecem a sua importancia para a caracterização da tuberculose, em nível de infecção, e enaltecem o seu valor em Saúde Püblica, fornecendo subsídios epidemiológicos básicos para que medidas sanitärias sejam adotadas para o controle da doença.

ARANTES $^{1}$ (1974) cita a importância do teste tu berculínico para distinguir doentes e não doentes em termos de sensibilidade e especificidade, sendo a sensibilidade a capacidade do teste dar um resultado positivo quando a pessoa testada é verdadeiramente doente, e especificidade, a capacidade de apresentar um resultado negativo quando a pes soa examinada não é doente. Quanto maior a sensibilidade de um teste, menor a ocorrência de falsos negativos, e quan to maior a especificidade, menores as possibilidades de fal sos positivos.

A sensibilidade do teste tuberculínico, avalia da em populações de doentes, alcança $98 \%$ de positividade, is to é, a probabilidade de resultados negativos em pessoas doentes $\bar{e}$ aproximadamente igual a $2 \%$.

Não obstante sua alta sensibilidade e especifí cificidade, a prova tuberculínica tipo Mantoux (PPD,Rt-23,2UT) apresenta reações cruzadas para as infecções por micobactérias atipicas e nas pessoas vacinadas pelo BCG (falsos po- 
sitivos), sendo igualmente possível apresentar-se negati va em organismos já infectados pelo Mycobacterium tuberculosis, que apresentam hipersensibilidade tuberculínica diminuída, abaixo do limiar de mensuração cutânea (falsos ne gativos).

Nas regiões onde são realizados estudos sōbre a infecção por micobactērias atípicas, e sua incidência é constatada, os individuos reatores fracos ao teste.tubercu inico (que apresentam reatividade tuberculinica de 5 a 9 mm de diâmetro), são frequentemente considerados como infectados pelas mesmas, e selecionados para os testes específicos.

Para detectar os prováveis infectados pelo M. tuberculosis entre os reatores fracos e os não reatores, tem sido preconizada, por alguns autores, a repetição do teste, depois de um certo período de tempo.

Estudos realizados pela OMS $^{15}$ (1955), em esco lares vacinados recentemente pelo $B C G$ e que se tornaram sen siveis à tuberculina, mostram que a repetição do teste tuberculínico no mesmo local onde foi feito anteriormente, apresenta diferença no tamanho e característica da reação que se forma, em relação àquela que se obtem quando o teste é repetido em local diferente.

As reações tuberculínicas que se formam na decorrência da aplicação do teste num local anteriormente 
testado, não parecem ter influência da reatividade tuberculinica induzida pelo teste prévio.

SILVEIRA \& MEDEIROS ${ }^{22}$ (1962), concluíram que a utilização de uma prova única nas concentrações então usadas PPD, Rt-23, I UT ou concentração a 1:1000, só vale para separar os individuos em reatores fortes e reatores fracos e nunca para distinguir os infectados dos que não o foram pelo M. tuberculosis. Considerando assim, o teste ünico, com dose minima de tuberculina, capaz de revelar os reatores for tes (hiperérgicos), deixa de lado um grande número de infectados, com alergia atenuada (mesérgicos e hipoérgicos) que, por serem falsos negativos, continuam a ser interpretados como se fossem virgens da infeção virulenta.

NARAIN ${ }^{14}$ (1968), mostrou através de estudo controlado da repetição do teste tuberculínico, que mesmo em lu gar diferente da aplicação prévia, poderá na segunda aplicação ocorrer uma reação significativamente maior que a primei ra, mesmo na ausência de nova infeção. Sendo isso mais comum em pessoas com alergia não específica.

RUFFINO NETO ${ }^{20}$ (1972), repetiu a prova tuberculí nica em pacientes com suspeita clínica de apresentar tubercu lose extra-pulmonar e pulmonar, para conseguir um diagnóstico diferencial. As reaplicações da prova foram feitas em outro braço ou em ponto de aplicação não previamente inoculado com tuberculina. Concluiu que alguns individuos pas saram a reagir positivamente, quando retestados com a mesma dose de $0,1 \mathrm{ml}$ de tuberculina a $1: 1000$, após apresentarem 
resultado negativo ou duvidoso no 1 i teste feito. Alegou tal fato ter ocorrido, devido a erros de técnica de leitura, e variações biológicas apresentadas pelo organismo testado, em virtude de circunstâncias que poderiam ter levado a um re sultado negativo ou duvidoso na primeira vez. Recomenda que nos serviços onde se efetua a prova tuberculínica com objetivo de diagnóstico diferencial, principalmente nos casos de suspeita de tuberculose pulmonar e na clínica pediátrica, é importante e repetição da prova com doses crescentes de tuber culina.

Para reforçar tais opiniões, foi verificado que em Medicina Veterinäria também são preconizados outro métodos de aplicação do teste tuberculínico, além da prova tuber culínica tipo Mantoux, para o diagnóstico da tuberculose bovina. Entre esses métodos, o mais usado é a prova de STORMONT ou prova tuberculínica dupla intradérmica, que consiste na aplicação de um segundo teste, no mesmo local, depois de 96 a 120 horas e leitura do mesmo após 24 horas.

Para GLOVER ${ }^{9}$ (1939), cujos estudos demonstraram que, após uma segunda aplicação da tuberculina num mesmo local, a reação tissular que se forma é muito mais nítida, com aumento da enduração em mais de $3 \mathrm{~mm}$ nos animais com reações po sitivas (doentes), e que não se altera nos animais com rea ções negativas (sadios). Isto ocorre, desde que haja um espaço de tempo entre a la. e a $2 a$. aplicações, tempo este necessārio para esgotar os anticorpos e provocar nos animais um período de não reatividade entre a 1 a. e $2 a$. pro vas. 
CABOT $^{3}$ (1938), cita que a prova dupla intradérmica com tuberculina, em animais, demonstrou que as reaçóes positivas tem sido observadas no 40 ou no 59 dia após a aplicação, sensibilizando os animais que se mostraram positivos ou com reações duvidosas na leitura final de 72 horas, após o inicio.

PRIESTLEY ${ }^{19}$ (1946), cita que a prova dupla intra dérmica chamada prova de STORMONT, confirma o resultado de que a reação à tuberculina é alérgica tardia com fenômeno tipo Arthus, em que os anticorpos estão ligados às células (anticorpos sēsseis linfocitários), isto é, que a la. inocula ção de alergeno atrai as células "sensibilizadas ao local e a segunda, provoca rapidamente uma reação porque o alergeno é injetado em local já sensibilizado. Estatisticamente, o autor demonstrou, também a possibilidade de resultados falsos positivos ou falsos negativos em uma variação de 2 a $10 \%$ no máximo, com alfa 0,05 , o que é muito considerável, quando comparado com a prova de Mantoux simples que apresenta uma varia ção de erro de $18 \%$ até $37 \%$, também a nível de alfa 0,05 , nos animais a ela submetidos.

Todos esses autores evidenciaram que, em animais, após uma segunda aplicação da tuberculina num mesmo local, a reação tissular é mais nítida, facilitando o diagnóstico da tuberculose nos casos duvidosos.

Baseando-se nesses trabalhos, a autora (GUEDES ${ }^{11}$, 1975), realizou uma pesquisa preliminar em adultos, onde foram testados com a prova simples tipo Mantoux e a prova du- 
pla intradérmica, 344 trabalhadores de duas indústrias no município de Botucatu, SP. Tal trabalho foi realizado da seguinte maneira: foi aplicado na população escolhida o PPD, Rt-23, 2UT conforme padronização da OMS, e realizada a leitu ra após 72 horas. Para os individuos que apresentaram endura ção com mais de $5 \mathrm{~mm}$ de diâmetro (reatores fracos e reatores fortes) foi aplicado, no dia da leitura, no mesmo local,a segunda dose de PPD, e nova leitura foi efetuada após 24 horas. Os individuos não reatores $(0$ a $4 \mathrm{~mm})$ foram excluí dos do trabalho. Após a leitura da segunda aplicação, os in dividuos reatores fracos ( 5 a $9 \mathrm{~mm}$ ) que mantiveram, que dimi nuíram ou aumentaram a enduração, em menos de $3 \mathrm{~mm}$, em relação à primeira leitura, foram também excluídos do trabalho. os que apresentaram um aumento de $3 \mathrm{~mm}$ ou mais sobre a primeira leitura, foram encaminhados para baciloscopia e cultura. Os individuos reatores fortes com enduração maior de 10 mm, foram também encaminhados para baciloscopia e cultura.

Os resultados dessa pesquisa mostraram:

- que as duas provas foram eficazes epidemiologicamente, porque não houve possibilidade de aparecimento de reação tipo falso negativo, istoé, um individuo infectado apresentar uma reação negativa;

- que a prova de Mantoux dupla detectou um maior número de indivíduos com infecção tuberculosa curada recentemente, istoé, fez com que a reação tissular apresentada pelos individuos reatores fracos à prova de Mantoux simples, se apresentasse mais nítida, com aumento da enduração, tornando-os individuos reatores fortes. 
Nessa pesquisa ficou evidenciada a viabilidade da aplicação da prova dupla intradérmica em seres humanos, e o seu valor como método de diagnóstico da sensibilidade tu berculínica na clínica e em Saúde Pública.

Para a elaboração do presente trabalho foram formuladas as seguintes hipóteses:

- A repetição da prova tuberculínica com PPD, Rt-23, 2 UT após 72 horas, oferece maior número de indiví duos reatores, quando comparada com a 1a. aplicação da mes ma .

- Não há diferença no tamanho da enduração nas leituras de 24,48 e 72 horas, tanto para a la. como para a 2a. aplicações do teste tuberculínico.

- A repetição da prova tuberculínica no mesmo local e em local diferente não apresenta alteração nos re sultados das leituras.

- As pessoas não reatores, vacinadas anteriormente com BCG-id, respondem positivamente a uma segunda aplicação do teste tuberculínico. 


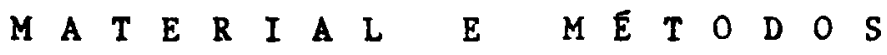

$13 ! \cdots !=?:$

rind

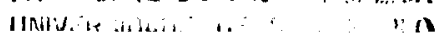


Este trabalho foi realizado em 3 unidades (A, B, C) da Fundação Estadual do Bem Estar do Menor (FEBEM) do Estado de são Paulo, no período de agosto a dezembro de 1977 .

A população de análise é constituída da totali dade de pessoas, de ambos os sexos, abrigadas na Institui çaó, durante um certo período de tempo.

Para a realização da prova tuberculínica foi empregado o PPD, Rt-23, do Staten Seruminstitut, diluído pela Unidade de Tuberculina do Laboratório de Referência da "Campanha Nacional Contra a Tuberculose", na dose de 0,04 mag por $0,1 \mathrm{ml}$ ( $2 \mathrm{UT}$ ), fornecido pelo" Centro de Säude "Geraldo de Paula Souza" da Faculdade de Saúda Pûblica da Universida de de são Paulo, sendo seguidas com o máximo rigor as recomendações técnicas em todas as etapas da mesma.

As seringas e agulhas foram do tipo "Tuberculin", padronizadas, assim como a régua milimetrada usada para a leitura das provas.

A aplicação e leitura das provas foram efetuadas pela própria autora, padronizada e aferida pelo Serviço Nacional de Tuberculose (SNT) e pela Secretariade Estado da Saúde de São Paulo. Na leitura foram considerados não reatores aqueles cuja enduração foi igual ou inferior a 4 $\mathrm{mm}$, reatores fracos os que tiveram de 5 a $9 \mathrm{~mm}$ e reatores fortes os que tiveram 10 ou mais mm de enduração. 
A coleta de dados teve as seguintes fases:

- aplicação indiscriminada na população escolhí da de PPD, Rt-23, 2 UT, na face anterior do antebraço E, con forme padronização da OMS e realizada a leitura da enduração, com régua milimetrada, depois de 24,48 e 72 horas;

- nos não reatores e reatores fracos, foi aplicado no dia da última leitura, um segundo teste tuberculíni co, constituindo-se por alternativas, em dois grupos:

a) em um grupo foi aplicado o novo teste no mesmo local da aplicação anterior:

b) no outro grupo foi aplicado o testena fá ce anterior do outro antebraço.

os individuos reatores fortes na primeira aplicação do teste foram excluídos do trabalho.

Para a anālise dos resultados, procurou-se ava liar a significancia das mudanças ocorridas nos resultados entre a 1a. e 2a. aplicações da prova tuberculínica, pelo teste de MacNemar, citado por FLEISS ${ }^{8}$ (1973).

Foram feitas tabelas de duplas entradas onde os resultados de ambas aplicaçóes foram categorizados em reato res e não reatores. No grupo de reatores foram incluídos aqueles individuos classificados como reatores fracos e rea tores fortes, nas leituras de 72 horas.

Säo comparados os resultados da la.e 2a. aplí cações da prova de Mantoux, quanto às seguintes variáveis: cor, leitura após 24,48 e 72 horas, se vacinado ou não an 
teriormente com BCG intradérmico ( BCG-id), idade e local da aplicação da 2a. prova, cujos resultados são apresentados em tabelas e figuras ilustrativas.

A população de análise é constituída de pessoas de 5 a 15 anos de idade que são analisadas conjuntamente, num só grupo.

A variāvel sexo não foi considerada por não influir na apresentação dos resultados.

Para análise das tres primeiras variáveis acima citadas, usou-se o Teste de $x^{2}$ (qui quadrado) com correção de continuidade descrito por Yates. Para avaliar os resultados da 2 a. prova quanto ao local de aplicação, usou-se a técnica de comparação por contrastes de Goodman, citado por PRANDI ${ }^{18}$, (1973).

Todos os testes utilizados no trabalho foram feitos ao nível de significância de 5\% - SPIEGEL ${ }^{24}$ (1971). 
R E S U L T A D O S E C C O M E N T A R I 
Participam do presente trabalho 439 pessoas de 5 a 15 anos de idade, pertencentes a tres Unidades da FEBEM,Es tado de São Paulo. (tabelas 1 e 2 ).

Dessa população de anälise, 401 ou $91,3 \%$ são do sexo masculino, 197 ou $44,9 \%$ de cor branca e 258 ou $58,8 \%$ do grupo etärio de 5 a 10 anos.

Nessas tabelas ficou evidenciado o maior número de pessoas do sexo masculino, de pessoas não brancas e de pessoas do grupo etärio de 5 a 10 anos.

Esses dados podem evidenciar a situação sócioeconômica das famílias a que pertencem, a maior solicitação das meninas para trabalhos de casa e a provável participaçào dos maiores de 10 anos, de ambos os sexos, em atividades fo ra do lar.

Nas Unidades onde a pesquisa foi realizada, foram aplicadas 439 provas e, devido a demissões e ou tranferências para outras Unidades da Instituição, foram lidas 415, cujas pessoas constituem o objetivo do presente trabalho (tä bela 3).

Essa tabela mostra os resultados da la. aplicação do teste tuberculínico, onde $196(47,2 \%)$ foram não reatores, $94(22,7 \%)$ reatores fracos, e $125(30,1 \%)$ reatores fortes, com um total de $219(52,8 \%)$ de reatores. 


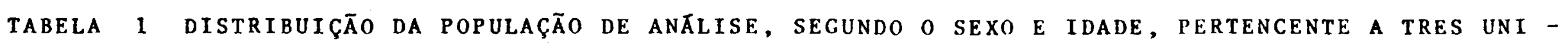

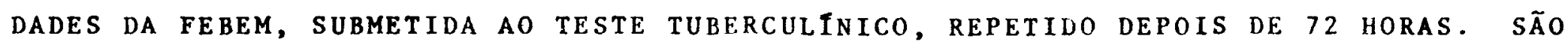
PAULO, 1977 .

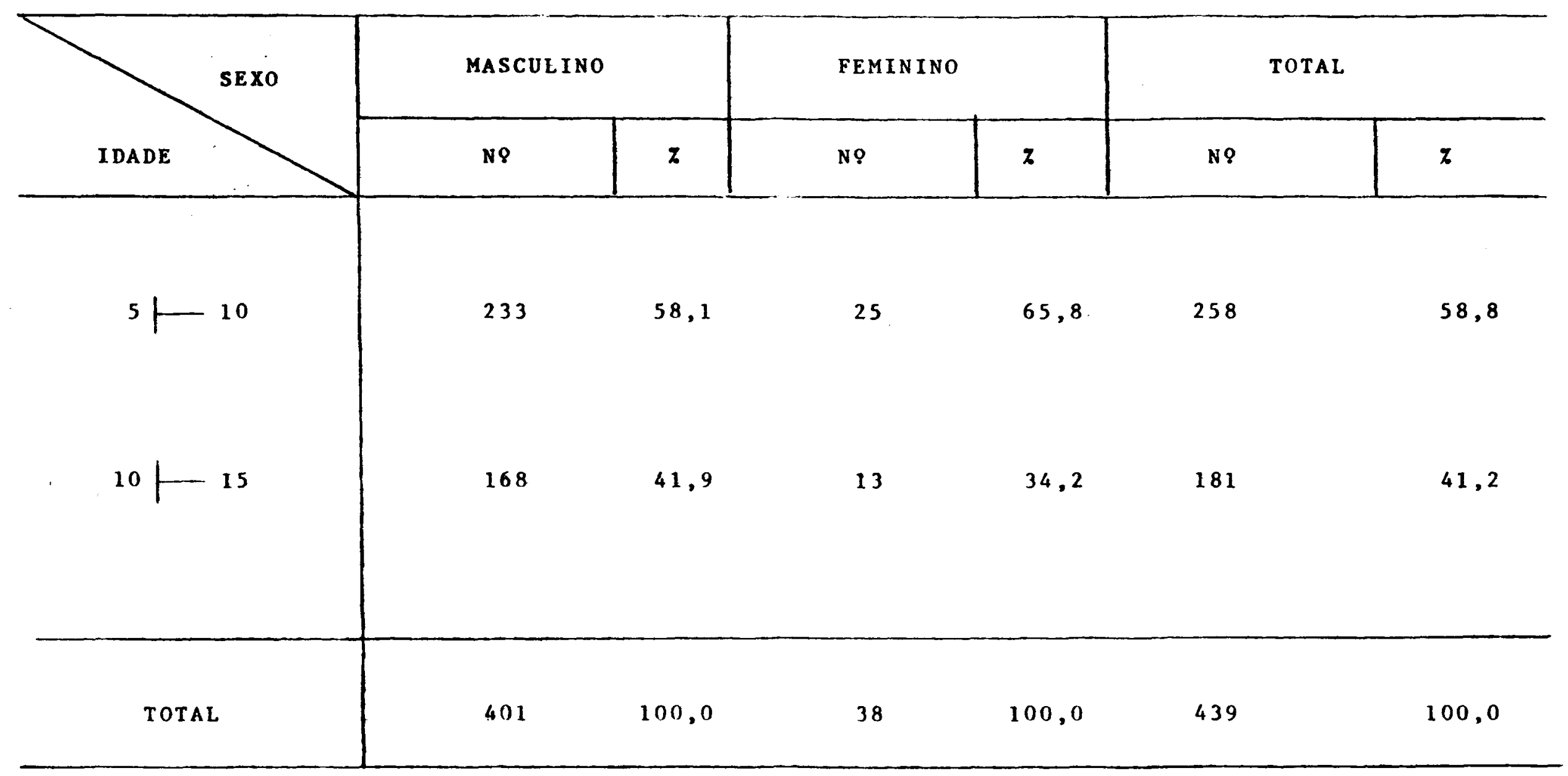




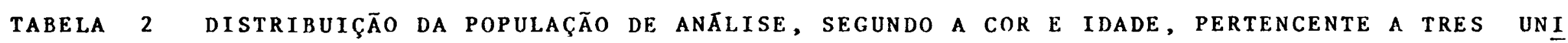
DADES DA FEBEM, SUBMETIDA AO TESTE TUBERCULINICO, REPETIDO APÓ 72 HORAS.SÃo PAULO, 1977.

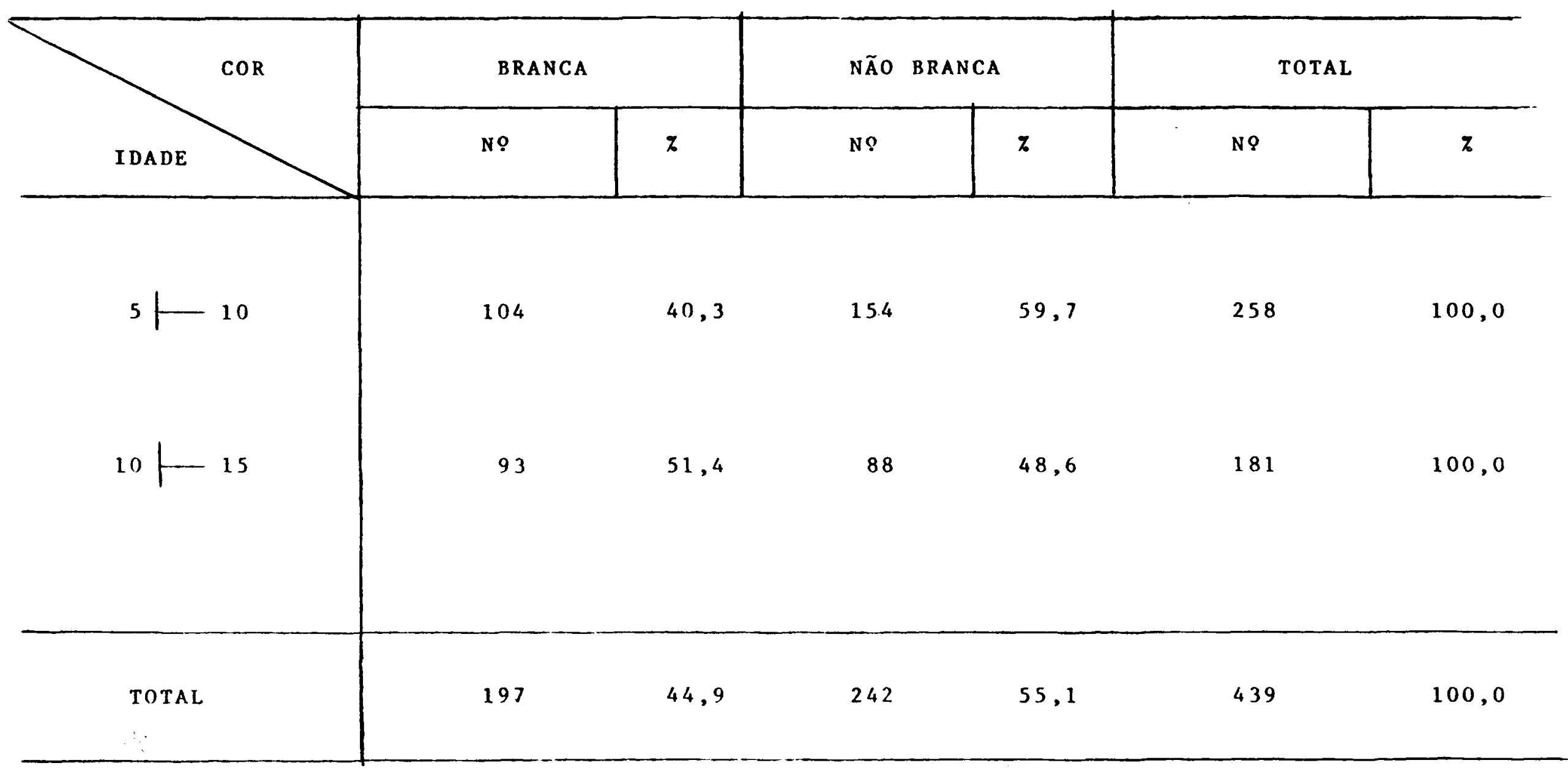


TABEla 3 Distribuição dos RESUltados da PRIMEIRA APLICAÇĀo do TESTE TUBERCUL INICO, EM PESSOAS de 5 a 15 Anos de idade, pertencentes a tres unidades da febem. São paulo. 1977.

\begin{tabular}{|c|c|c|c|c|c|c|c|c|c|c|}
\hline \multirow[b]{2}{*}{ UNIDADE } & \multirow{2}{*}{ FEITO } & \multirow{2}{*}{ L I DO } & \multicolumn{2}{|c|}{ NÃO REATOR } & \multicolumn{2}{|c|}{ REATOR FRACO } & \multicolumn{2}{|c|}{ REATOR FORTE } & \multicolumn{2}{|c|}{$\begin{array}{c}\text { TOTAL } \\
\text { REATORES }\end{array}$} \\
\hline & & & No & z & No & \% & No & $z$ & NQ & $z$ \\
\hline A & 94 & 93 & 23 & 24,7 & 31 & 33,4 & 39 & 41,9 & 70 & 75,3 \\
\hline B & 247 & 239 & 133 & 55,6 & 48 & 20,1 & 58 & 24,3 & 106 & 44,3 \\
\hline C & 98 & 83 & 40 & 48,2 & 15 & 18,1 & 28 & 33,7 & 43 & 51,8 \\
\hline TOTAL & 439 & 415 & 196 & 47,2 & 94 & 22,7 & 125 & 30,1 & 219 & 52,8 \\
\hline
\end{tabular}


Como parte da população de anālise foi vacinada com BCG-id, a elevada reatividade tuberculínica encontrada pode ser atribuída não apenas à infecção natural, mas também à vacinação pelo BCG.

A tabela 4 mostra a distribuição dos não reatores e totais de reatores, onde no grupo etário de 5 a 10 anos, 121 ou $49,2 \%$ são não reatores e 125 ou $50,8 \%$ são reatores e, no grupo de 10 a 15 anos, 75 ou $44,4 \%$ são não rea tores e 94 ou $55,6 \%$ são reatores, para um total de 196 ou $47,2 \%$ de não reatores e 219 ou $52,8 \%$ de reatores.

A tabela 5 apresenta os resultados da 2 a. aplicação do teste tuberculínico.

De acordo com a metodologia do trabalho, das 415 pessoas submetidas a la. prova (tabela 3 ), foram excluídas 125 para a 2 a. prova, por terem sido classificadas como rea tores fortes, e das 290 restantes, que se submeteram à $2 a$. aplicação do teste tuberculínico, foram lidos 263 , cujos re sultados são os seguintes: $93(35,4 \%)$ de não reatores, 142 $(54,0 \%)$ de reatores fracos e $28(10,6 \%)$ de reatores fortes, para o total de $170(64,6 \%)$ de reatores.

Das pessoas que se comportaram na la. prova, co mo reatores fracos ou não reatores, 28 ou $10,6 \%$ pertencentes às Unidades $B$ e $C$, se converteram em reatores fortes.

A tabela 6 mostra os resultados da $2 a$. aplica ção do teste tuberculínico, pór grupos etários. 


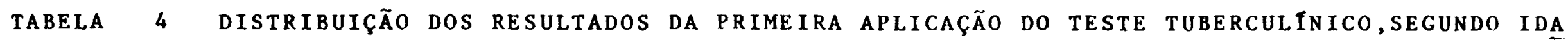

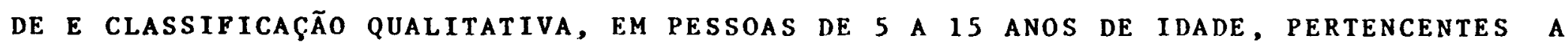
TRES UNIDADES dA FEBEM. SÃo PAULO, 1977.

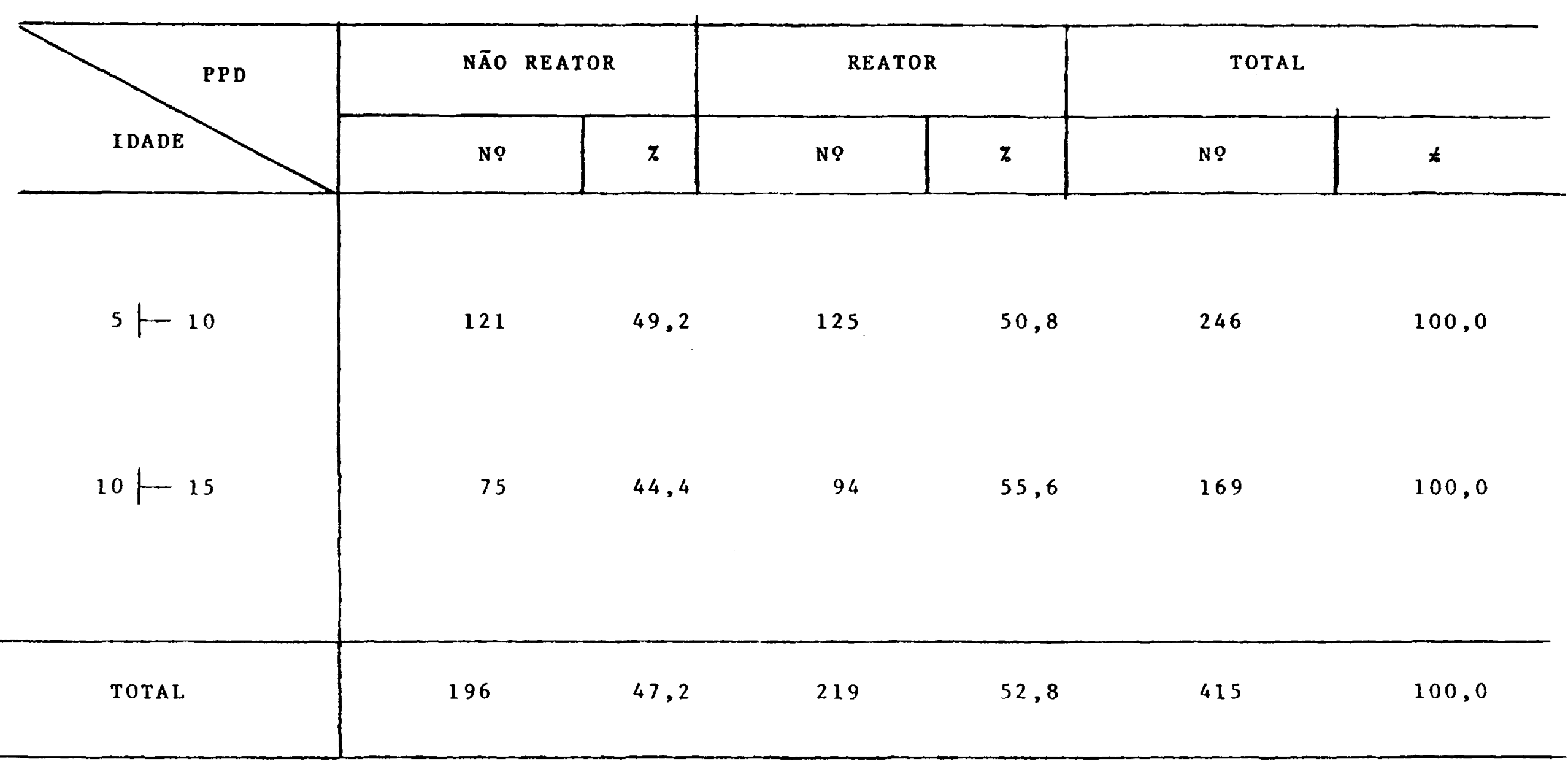




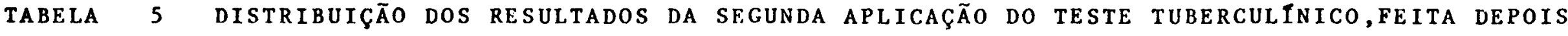
DE 72 HORAS, EM PESSOAS DE 5 A 15 ANOS DE IDADE, PERTENCENTES A TRES UNIDADES DA FEBEM. SÃo PAULO, 1977 .

\begin{tabular}{|c|c|c|c|c|c|c|c|c|c|c|}
\hline \multirow{2}{*}{ UN I DADE } & \multirow[t]{2}{*}{ FE ITO } & \multirow{2}{*}{ L I DO } & \multicolumn{2}{|c|}{ NÃO REATOR } & \multicolumn{2}{|c|}{ REATOR FRACO } & \multicolumn{2}{|c|}{ REATOR FORTE } & \multicolumn{2}{|c|}{$\begin{array}{c}\text { TOTAL } \\
\text { REATORES }\end{array}$} \\
\hline & & & No & $\%$ & No & $\%$ & No & $z$ & No & $\%$ \\
\hline A & 56 & 54 & 15 & 27,8 & 39 & 72,2 & - & - & 39 & 72,2 \\
\hline B & 179 & 156 & 63 & 40,4 & 73 & 46,8 & 20 & 12,8 & 93 & 59,6 \\
\hline c & 55 & 53 & 15 & 28,3 & 30 & 56,6 & 8 & 15,1 & 38 & 71,6 \\
\hline TOTAL & 290 & 263 & 93 & 35,4 & 142 & 54,0 & 28 & 10,6 & 170 & 64,6 \\
\hline
\end{tabular}


No grupo de 5 a 10 anos, 65 ou $40,1 \%$ são não rea tores e 97 ou $59,9 \%$ são reatores, e no grupo de 10 a 15 anos, 28 ou $27,7 \%$ são não reatores e 73 ou $72,3 \%$ são reatores, pa ra um total de 93 ou $35,4 \%$ de não reatores e 170 ou $64,6 \%$ de reatores.

A tabela 7 mostra os resultados comparativos da 1a. e 2a. aplicações do teste tuberculínico.

Dos 176 não reatores da 1a. aplicação, 77 ou 43,8\% se mantiveram não reatores, 94 ou $53,4 \%$ passaram para reatores fracos e 5 ou $2,8 \%$ para reatores fortes, na segunda aplicação.

As pessoas não reatoras nas duas provas $(77$ ou $43,8 \%$ ), podem ser consideradas como não infectadas pelo bacilo da tuberculose, havendo menor probabilidade de serem fal sos negativos por "erro de leitura do teste, ou por fatores individuais como desnutrição, infecções anergisantes recen tes ou uso de corticosteróides". (D.N.T.5,6 1967, 1968).

Das 87 pessoas reatores fracos na la. aplicação, 48 ou $55,2 \%$ mantiveram-se na mesma classificação no $2 \%$ teste, cujo fato pode identificar que houve confirmação de reativida de tuberculínica nas duas aplicações.

A segunda aplicação detectou maior número de reatores fracos em relação à primeira aplicação, respectivamente 142 e 87.

o total de reatores fracos $\dot{n} a$ 2a. aplicação 
TABELA

6 DISTRIBUIÇÃO DOS RESULTADOS DA SEGUNDA APLICAÇÃO DO TESTE TUBERCULINICO, SEGUNDO IDADE E ClassificaÇÃo QUALITATIVA, EM PESSOAS DE 5 A 15 ANOS DE IDADE, PERTENCENTES A TRES UNIDADES DA FEBEM. SĀO PAULO, 1977 .

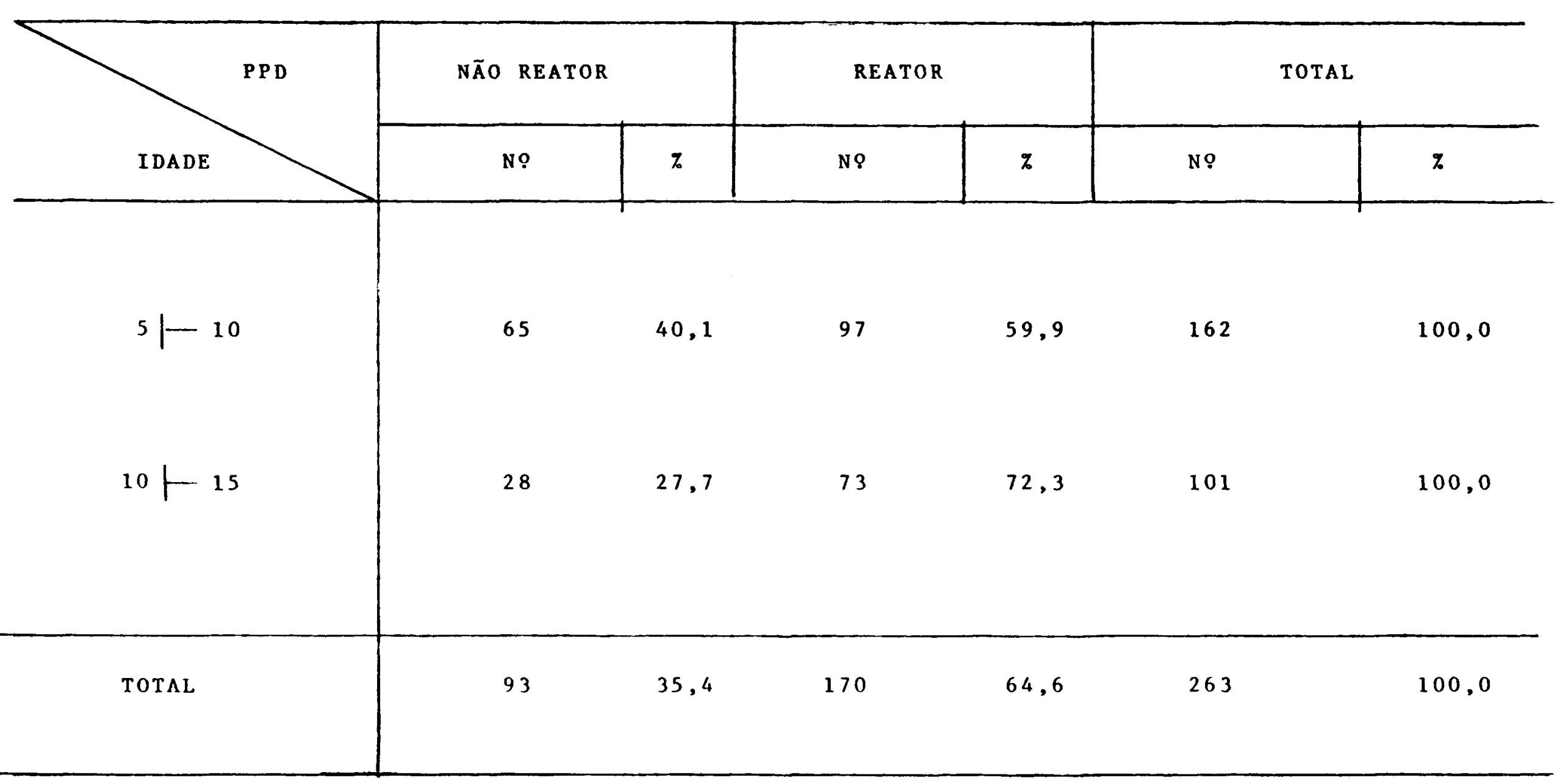




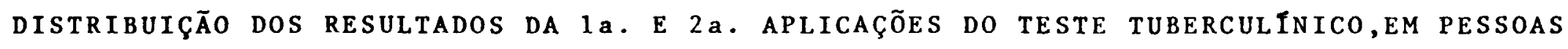
de 5 a 15 anos de idade, pertencentes a tres unidades da febem. São paulo, 1977.

\begin{tabular}{|c|c|c|c|c|c|c|c|c|c|}
\hline \multirow[b]{2}{*}{$1 \mathrm{a}}$. & \multirow[t]{2}{*}{$\begin{array}{c}\text { NQ } \\
\text { CASOS }\end{array}$} & \multicolumn{2}{|c|}{ NĀO REATOR } & \multicolumn{2}{|c|}{ REATOR FRACO } & \multicolumn{2}{|c|}{ REATOR FORTE } & \multicolumn{2}{|c|}{$\begin{array}{c}\text { TOTAL } \\
\text { REATORES }\end{array}$} \\
\hline & & N 8 & $\pi$ & NQ & $\%$ & No & $z$ & No & $z$ \\
\hline NÃO REATOR & 176 & 77 & 43,8 & 94 & 53,4 & 5 & 2,8 & 99 & 56,2 \\
\hline REATOR FRACO & 87 & 16 & 18,4 & 48 & 55,2 & 23 & 26,4 & 71 & 81,6 \\
\hline TOTAL & 263 & 93 & 35,4 & 142 & 54,0 & 28 & 10,6 & 170 & 64,6 \\
\hline
\end{tabular}


(142) está fortemente influenciado pelo número de não reatores da 1a. aplicação que se converteram em reatores fracos na segunda aplicação.

o fato de não reatores passarema reatores fracos, pode ser devido a erros de leitura ou à sensibilização dos linfócitos $T$, mobilizados pela la. aplicação da tubercü lina, capazes de induzir à reatividade na $2 a$. aplicação.

Como afirmam alguns autores, nas regiöes onde é conhecida a infeção por micobactérias atípicas, a baixa reatividade tuberculínica pode ser atribuída às mesmas. (PAZ DE ALMEIDA 17,1974 , BROLIO et a ${ }^{2}, 1976$, MAGALDI $\left.^{12}, 1976\right)$.

A mesma tabela 7 mostra que de 87 reatores fra cos da 1a. aplicação, 16 ou $18,4 \%$ passarama não reatores, ocorrência que pode ser atribuída à diferença de leitura, visto que foram utilizadas a mesma substância e a mesma téc nica nas duas aplicações, se bem que este evento pode ser atribuído também, à possibilidade da primeira inoculação tuberculinica poder provocar um fenómeno de tolerância imuno lógica e consequente dessensibilização para essa substância.

A tabela 8 mostra os não reatores e totais de reatores das duas aplicações, apresentados na tabela 7 .

A anālise desses resultados pelo teste de MacNemar evidencia, estatisticamente, a diferença significante ao nível proposto, de reatores na $2 a$, em relação à $1 a$ apli cação da prova tuberculínica. 


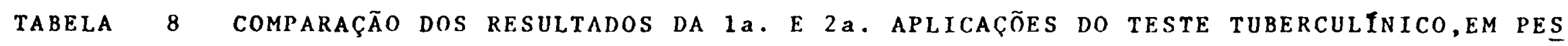
SOAS de 5 a 15 anos de idade, Pertencentes a tres unidades da febem. São paulo, 1977.

\begin{tabular}{|c|c|c|c|c|c|c|}
\hline $2 a \cdot A P L I C A C ̧ A ̃$ & \multicolumn{2}{|c|}{ NÃO REATOR } & \multicolumn{2}{|c|}{ REATOR } & \multicolumn{2}{|c|}{ TOTAL } \\
\hline I a . A P L I CAÇĀO & No & $\%$ & $\mathrm{NS}$ & $\pi$ & No & $\%$ \\
\hline NÃO REATOR & 77 & 43,8 & 99 & 56,3 & 176 & 100,0 \\
\hline REATOR & 16 & 18,4 & 71 & 81,6 & 87 & 100,0 \\
\hline TOTAL & 93 & 35,4 & 170 & 64,6 & 263 & 100,0 \\
\hline
\end{tabular}

$$
\begin{gathered}
x_{1 g 1}^{2}=58,47 \\
x_{1}^{2}>x_{5 \% ; 1}^{2}
\end{gathered}
$$


o mesmo resultado foi encontrado por PRIESTLEY 19 (1946), NARAIN ${ }^{14}$ (1968) e RUFFINO NETO ${ }^{20}$ (1972), que obtiveram com a repetição da prova tuberculínica depois de um certo tempo, uma reação maior do que a da primeira.

A tabela 9 e as figuras $1,2,3,4$ e 5 apresentam a distribuição e a representação gräfica dos resultados das me didas das reações tuberculínicas, respectivamente de 24,48 e 72 horas, da la. e $2 a$. aplicações do teste tuberculínico.

A anālise dos resultados dessa tabela e das figuras 1 e 2 , mostra pelo desvio padrão, que não houve diferen ça significante nas leituras de 24,48 e 72 horas, para a $1 a$. e 2 a. aplicações do teste.

Na 1a. prova, o desvio padrão foi decrescente nas três leituras, provavelmente por traumatismo do tecido no local da plicação do teste, revelando as reações tuberculínicas específicas depois de 72 horas.

Contrariando ao que foi obtido por ARANTES ${ }^{1}$ (1974) e por RUFFINo NETo 21 (1974) que não encontraram dife rença nos diâmetros de enduração na prova tuberculínica, quan do lida com 48,72 e 96 horas, o que foi constatado igualmente em trabalho publicado pela OMS ${ }^{15}$ (1955), relativo às leituras de testes tuberculínicos feitos diariamente, durante cinco dias consecutivos, em que não houve diferença significa tiva entre os resultados das respectivas leituras.

Na 2a. prova, o desvio padrão apresentou um com- 
distribuição dos resultados das medidas, em mm, das médias, desvios padrões e coefi CIENTES de Variação, das provas tuberCuLÍnicas, SEgundo as aplicaÇões e os tempos de LEITURA, EM PESSOAS dE 5 A 15 ANOS DE IDADE, PERTENCENTES A TRES UNidAdes da febem. SÃo PAULO, 1977 .

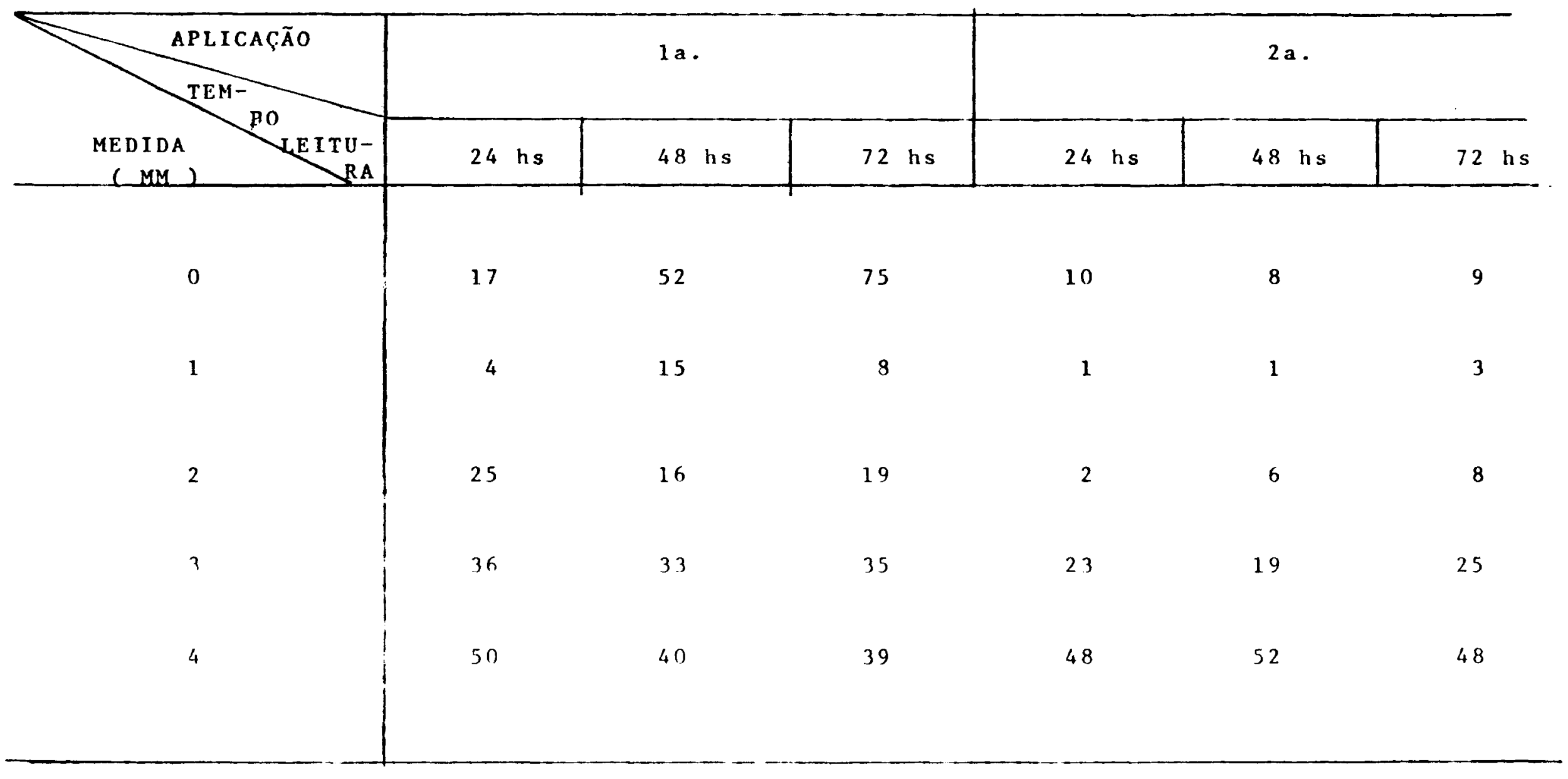




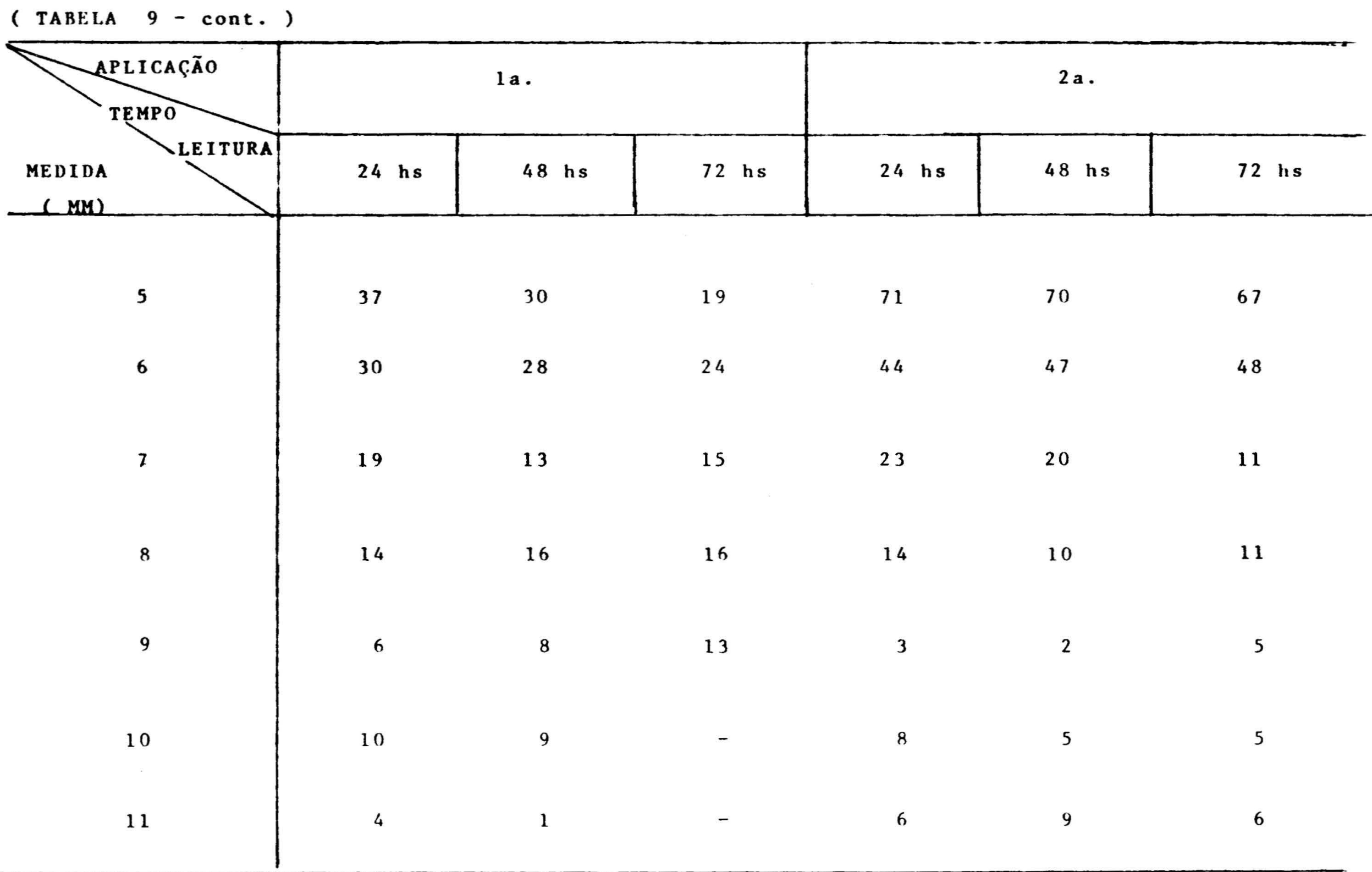


(TABELA 9 - cont.)

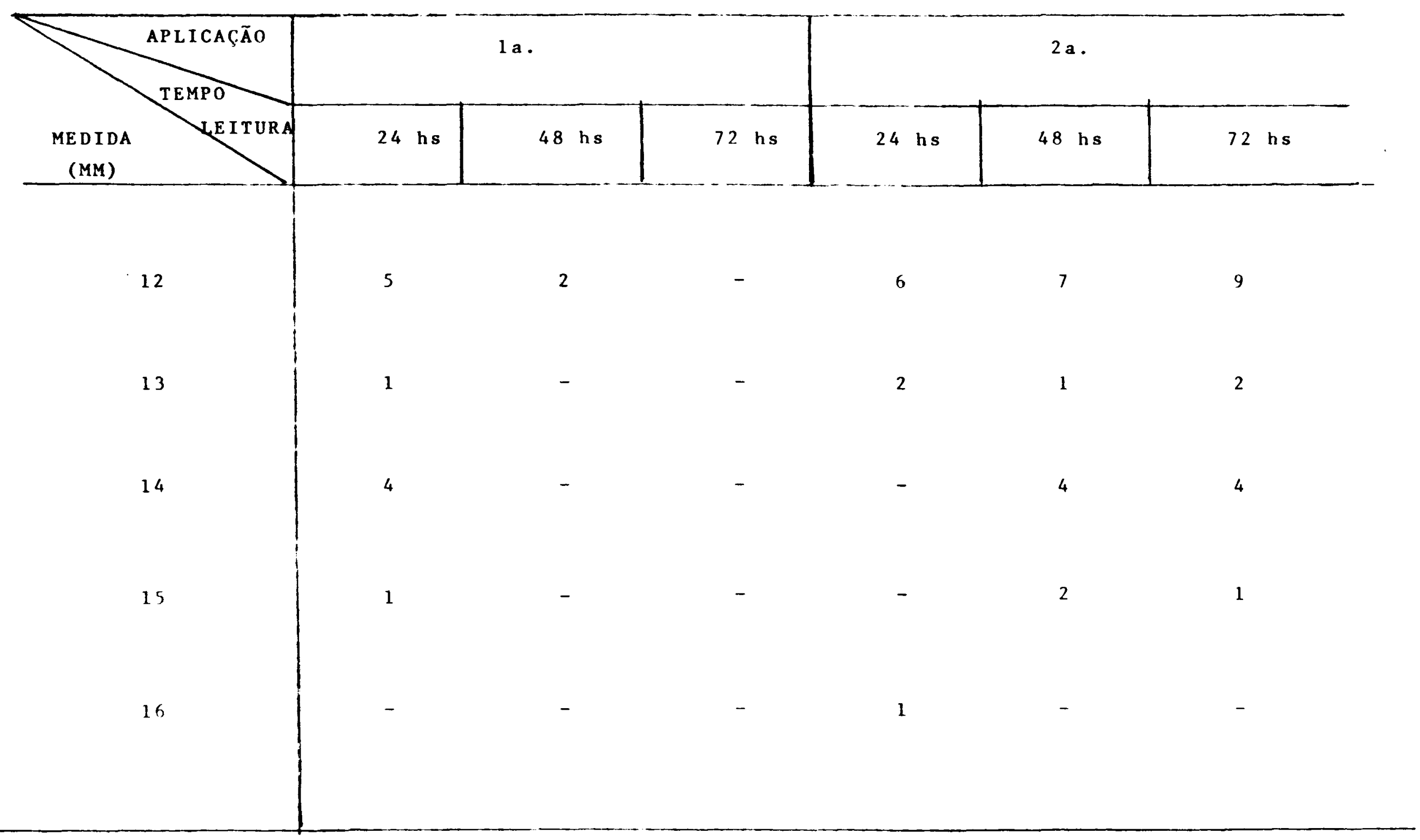


(TABELA 9 - cont.)

\begin{tabular}{|c|c|c|c|c|c|c|}
\hline APLICA & \multicolumn{3}{|c|}{$1 \mathrm{a}$} & \multicolumn{3}{|c|}{$2 \mathrm{a}$} \\
\hline $\begin{array}{r}\text { ME DI DA } \\
\text { (MM) }\end{array}$ & $24 \mathrm{hs}$ & $48 \mathrm{hs}$ & 72 hs & $24 \mathrm{hs}$ & $48 \mathrm{hs}$ & $72 \mathrm{hs}$ \\
\hline 17 & - & - & - & - & - & 1 \\
\hline 18 & - & - & - & 1 & - & - \\
\hline TOTAL & 263 & 263 & 263 & 263 & 263 & 263 \\
\hline $\bar{x}$ & 5,00 & 3,95 & 3,40 & 5,56 & 5,62 & 5,54 \\
\hline$D P$ & 3,00 & 2,95 & 2,84 & 2,61 & 2,76 & 2,87 \\
\hline C V & 0,60 & 0,74 & 0,83 & 0,46 & 0,49 & 0,51 \\
\hline
\end{tabular}


Figura I Distribuiçño dos RESUltados das MEdidas, EM MM, DA Ia.AplicaÇão da PROVA TUBERCULINICA, SEGUNDO OS TEMPOS DE LEITURA, EM PESSOAS DE 5

A 15 anos de idade, pertencentes a tres unidades da febem. São paulo,

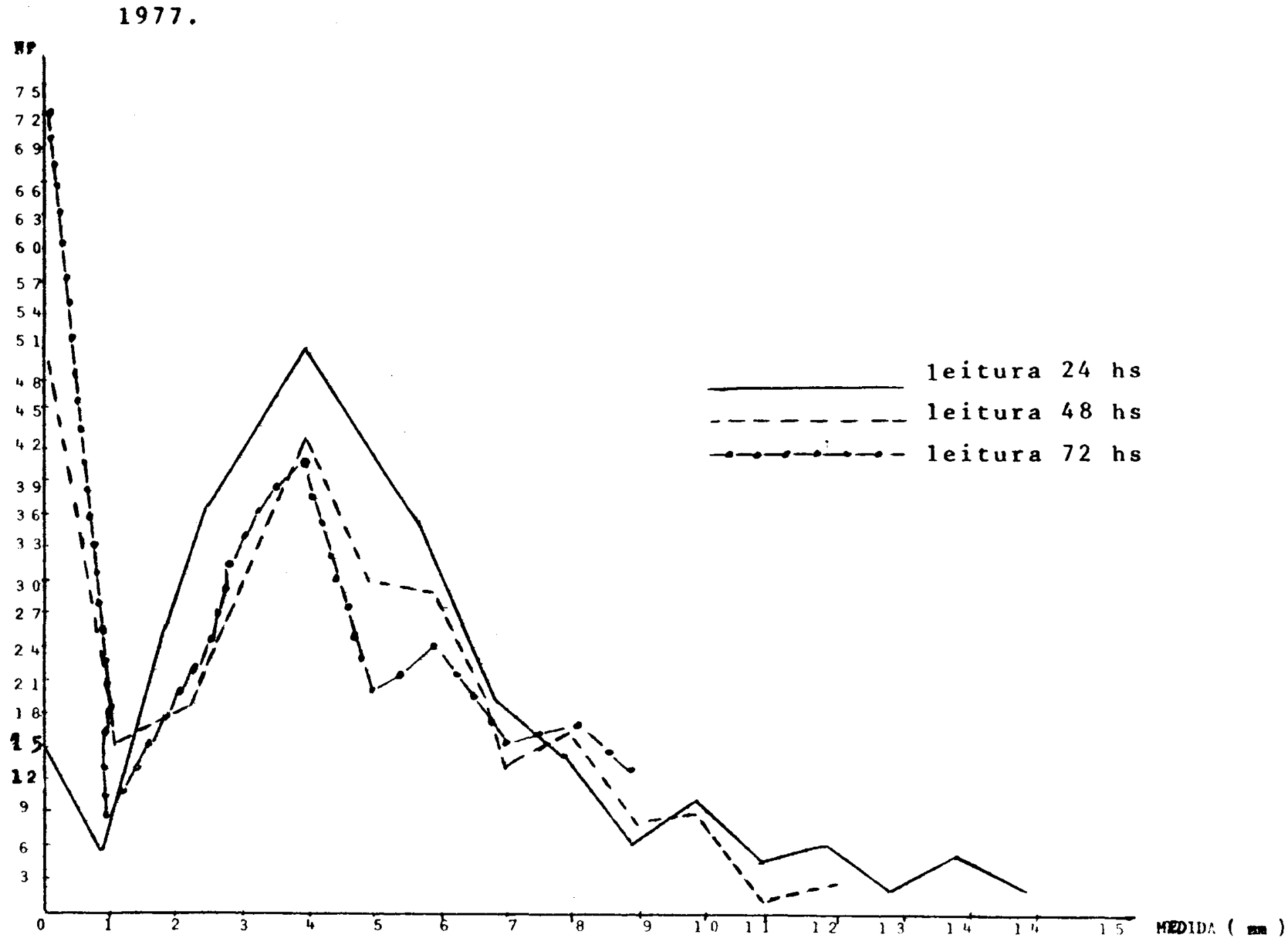




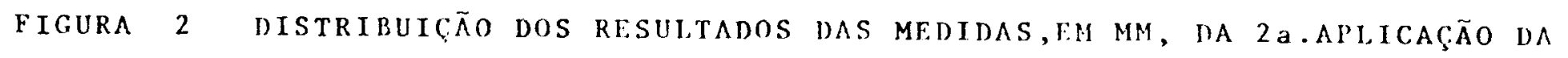
PROVA TUBERCULINICA, SEgUNDO OS TEMPOS DE LEITURA, EM PESSOAS DE 5 A

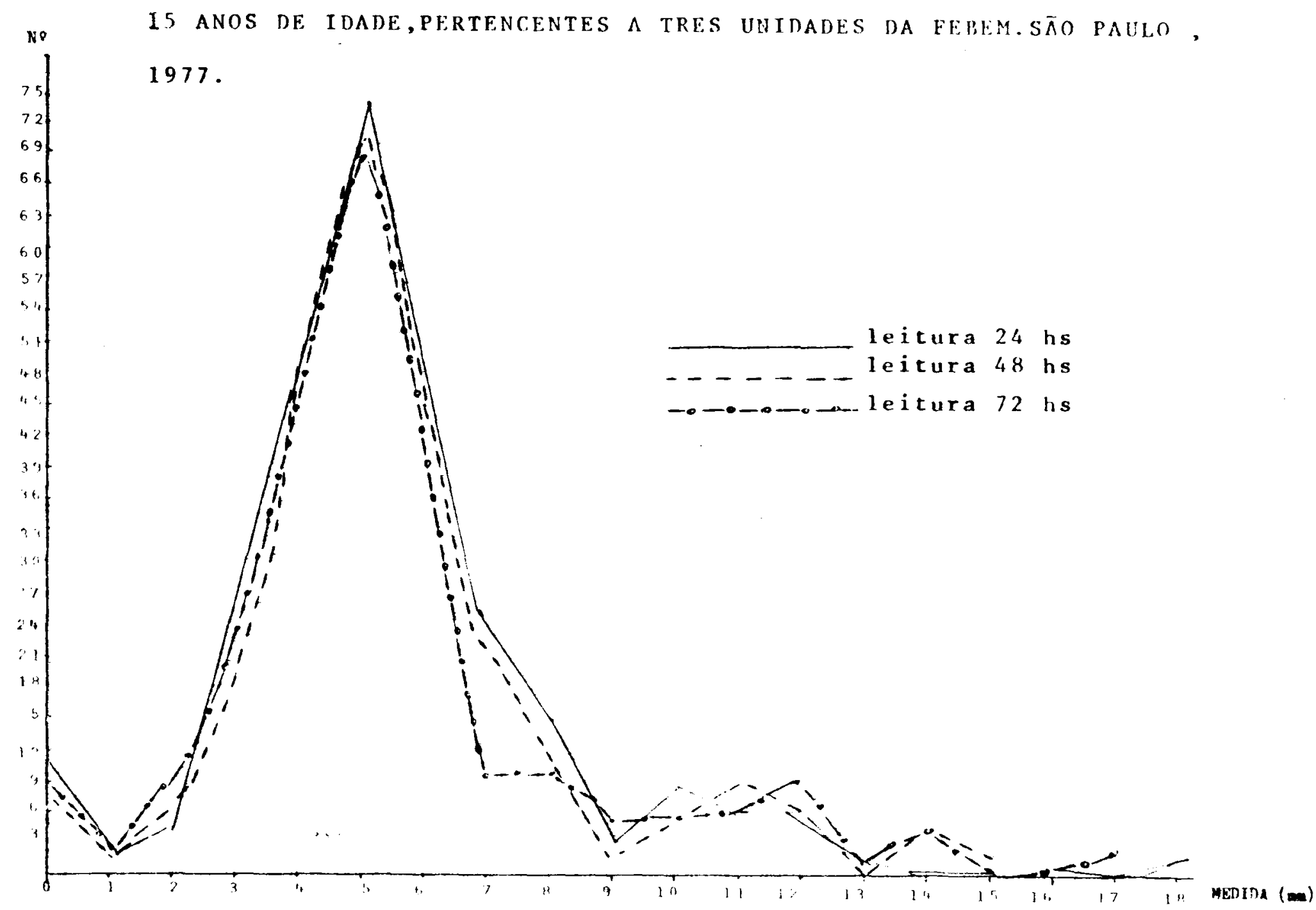


portamento crescente, provavelmente pelo efeito "booster", por ativação dos linfócitos de memória, mobilizados para o local de aplicação, em individuos previamente infectados.

Os coeficientes de variação foram crescentes nas duas provas, mostrando provavelmente a influência de fatores traumáticos no local de aplicação, nas leitura de 24 e 48 horas, confirmando as reações específicas nas leituras de 72 horas.

A comparação dos coeficientes de variação, da tä bela 9 , nos mesmos tempos de leitura das duas provas, mostra que nas leituras de 24 horas houve uma diferença dos mesmos de 0,14 .

Na figura 3 , as curvas praticamente se superpõem, com ponto mais elevado em $4 \mathrm{~mm}$ de enduração na primeira aplicação e em $5 \mathrm{~mm}$ na segunda, decrescendo até $9 \mathrm{~mm}$, e prolongando-se até $15 \mathrm{~mm}$ na $1 \mathrm{a}$. e até $18 \mathrm{~mm}$ na $2 \mathrm{a}$. aplicação.

A figura 4, das leituras de 48 horas, cuja diferença dos coeficientes de variaşa é de 0,25 , mostra curvas semelhantes às das leituras de 24 horas, com maior concentra ção de reatores na $2 a$ aplicação.

A figura 5, das leituras de 72 horas, cuja diferença dos coeficientes de variação é de 0,32 , mostra que até $9 \mathrm{~mm}$ de enduração, as curvas são semelhantes às anteriores, apresentando uma diferença nítida nas mensurações mais eleva das da 2a. aplicação, confirmando o efeito "booster" do tes 


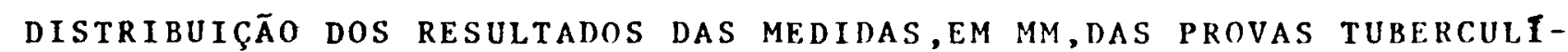
NICAS, SEgUNDO AS APLICAÇÕES F. LEITURAS DE 24 HORAS, EM PESSOAS DE 5

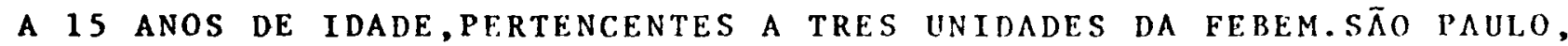

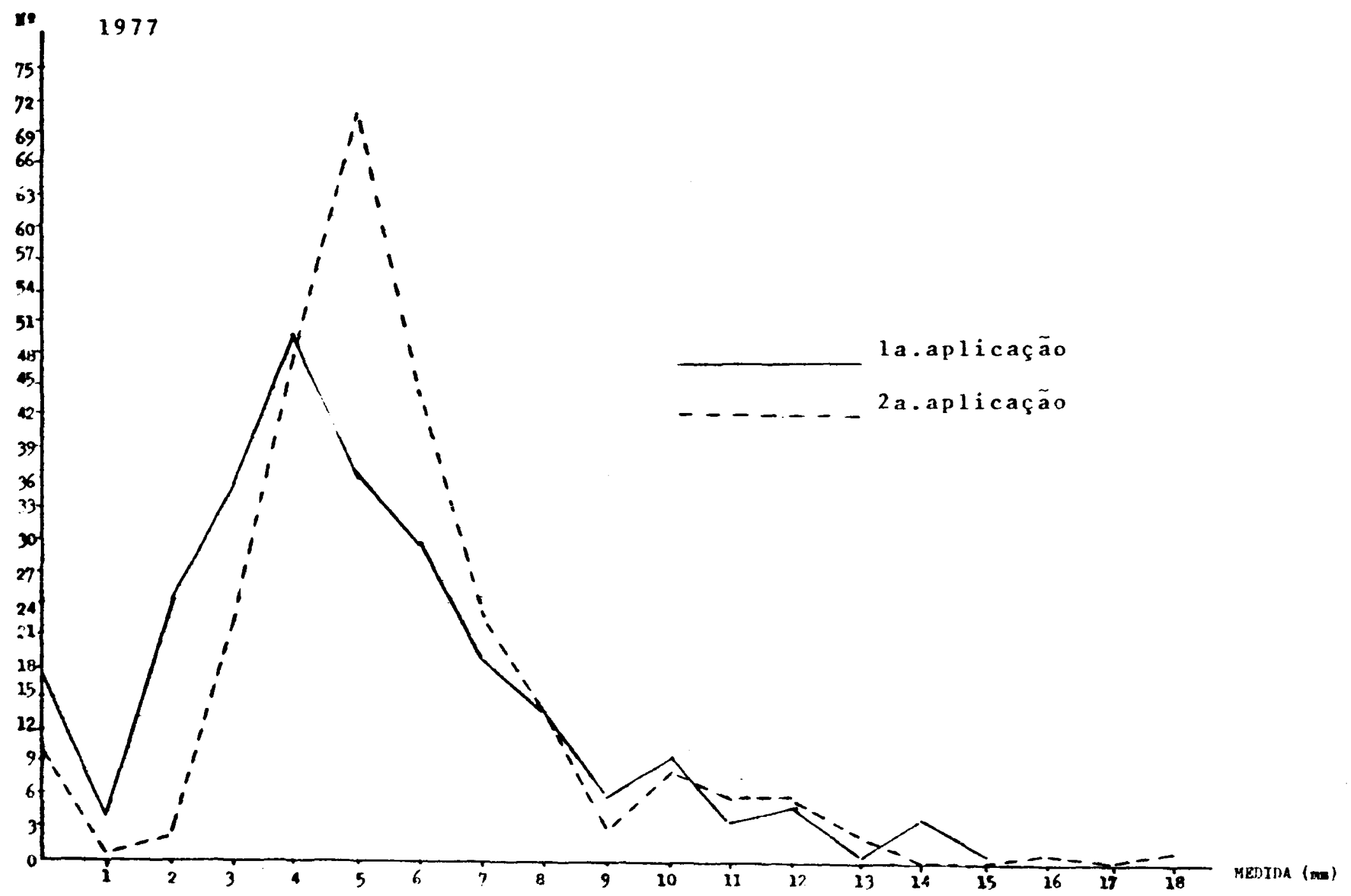




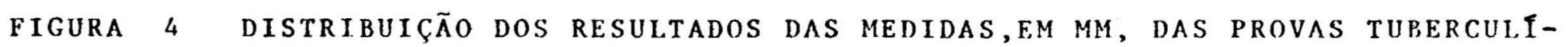
NICAS, SEgundo AS APLiCaÇões f leituras de 48 HORAS, EM PESSOAS DE 5
A 15 ANOS DE IDADE, PERTENCENTES
A TRES UNIDADES
DA FEBEM. ST̃o PAULO,

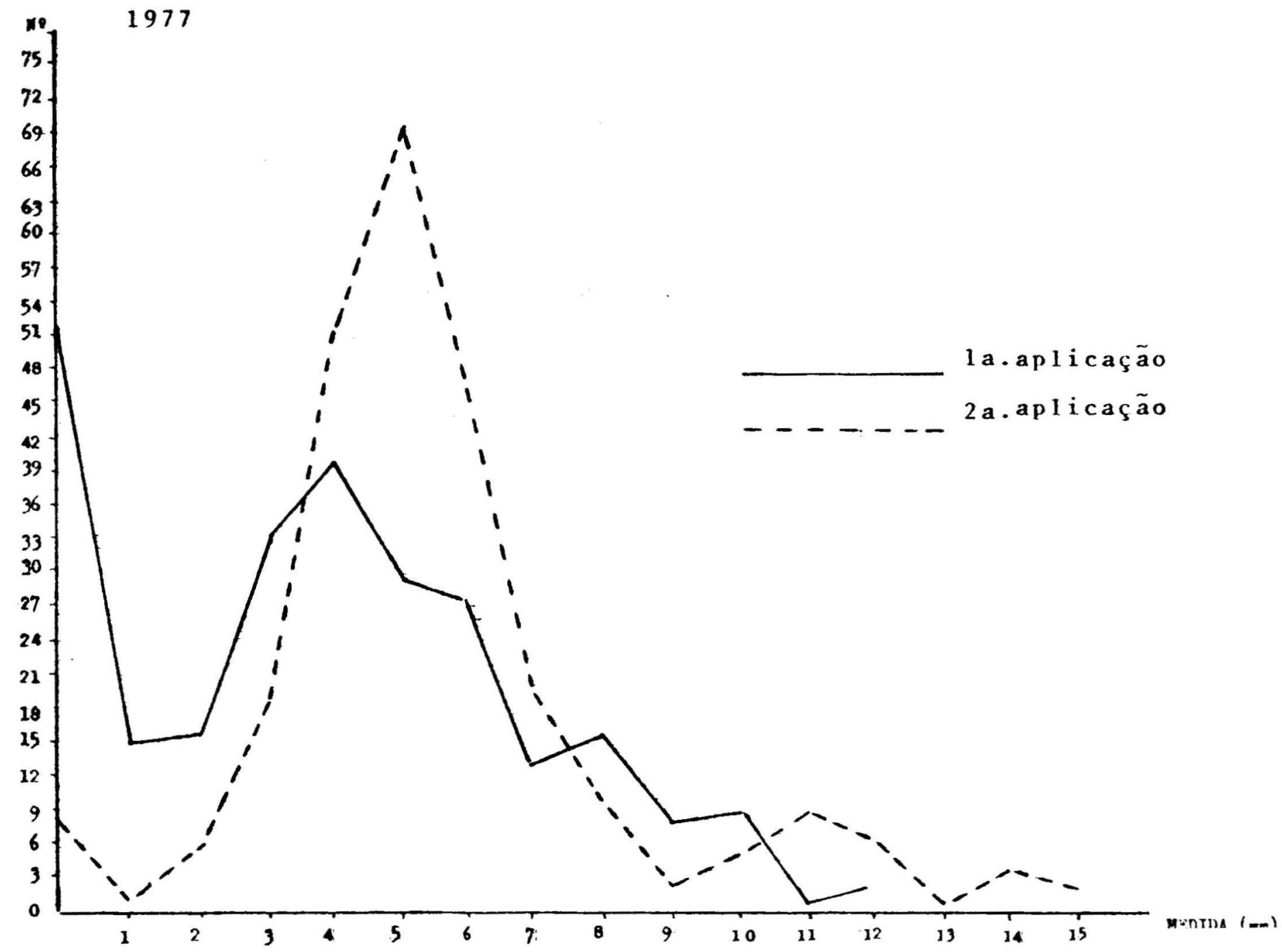


UISTRIBUICÃO DAS RESULTADOS DAS MEDIDAS, EM MM, DAS PROVAS TUBERCULINICAS, SEGUNDO AS APLICAÇÕES E LEITURAS DE 72 HORAS, EM PFSSOAS DF 5

A 15 ANOS DE IDADE, PERTENCENTES $\Lambda$ TRES URIDADES IAA FEBEM.SÃO PAIIOO,

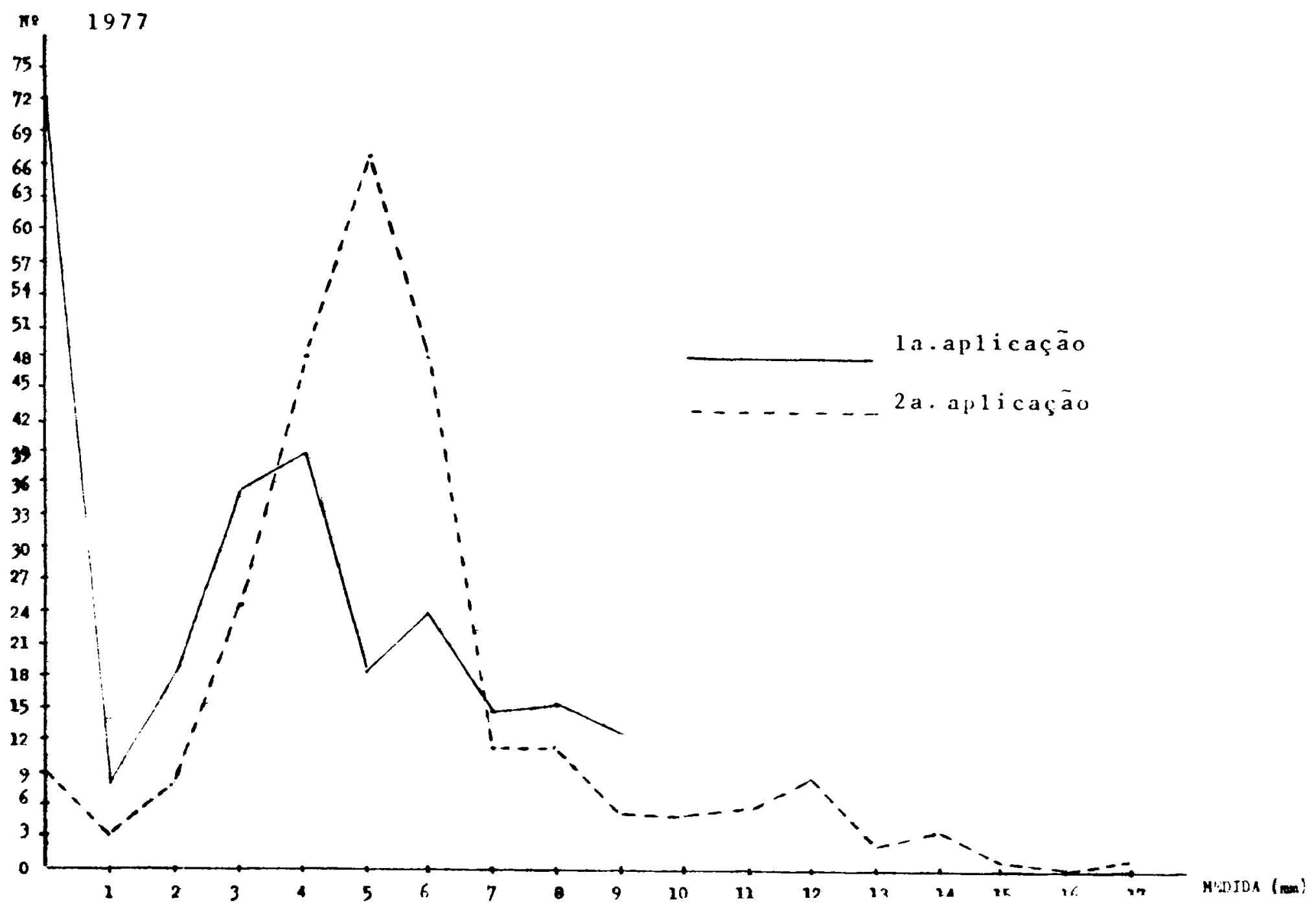


te tuberculínico repetido.

Náo obstante os maiores percentuais de resultados positivos nas leituras de 24 horas pela prova de stor mont, em Medicina Veterinária, como evidenciam os estudos de CABOT $^{3}$ (1938), GLOVER ${ }^{9}$ (1939), PRIESTLEY ${ }^{19}$ (1946) e GOTTSCHALK ${ }^{10}$ (1971), os resultados do presente trabalho parecem evidenciar que as leituras de 72 horas, revelam maior número de reatores, com menor possibilidade da influência de fatores traumáticos locais, que podem existir naleitura de 24 horas.

A tabela 10 mostra a distribuição dos resultados das duas aplicações do teste tuberculínico, segundo os tempos de leitura, onde pode ser verificado que os não reatores predominam nas tres leituras da primeira aplicação. o mesmo nào ocorrendo com os totais de reatores que apresentam percentuais mais elevados na 2 a. aplicação.

Estudando a variável cor, a tabela ll, da la. apli cação, mostra que de 113 pessoas de cor branca, 85 ou $75,2 \%$ são não reatores e 28 ou $24,8 \%$ são reatores, e de 150 pes soas não brancas, 91 ou $60,7 \%$ são não reatores e 59 ou $39,3 \%$ são reatores. Houve maior percentual do total de não reatores, e entre os reatores, maior percentual nas pessoas näo brancas.

Na 2a. aplicação (tabela 12), das 113 pessoas de cor branca, 43 ou $38,0 \%$ são não reatores e 70 ou $62,0 \%$ são reatores, e de 150 pessoas não brancas, 50 ou $30,3 \%$ são não reatores e 100 ou $66,7 \%$ são reatores. Houve menor percentual 
tABEla 10 Distribuição dos Resultados SEgundo a Classificação Qualitativa da 1a. E 2 a. Aplica

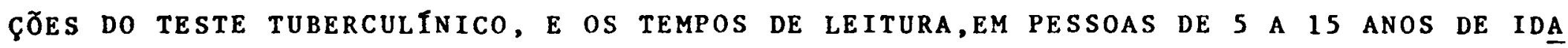
De, Pertencentes a tres unidades da febem. São Paulo, 1977.

\begin{tabular}{|c|c|c|c|c|c|c|c|c|c|c|c|c|}
\hline ApLICaç & \multicolumn{6}{|c|}{$1 \mathrm{a}$. } & \multicolumn{6}{|c|}{$2 a$. } \\
\hline $\begin{array}{l}\text { MEDIDA } \\
(M M)\end{array}$ & $24 \mathrm{hs}$ & $\%$ & $48 \mathrm{hs}$ & $\pi$ & $72 \mathrm{hs}$ & $z$ & $24 \mathrm{hs}$ & $z$ & $48 \mathrm{hs}$ & $z$ & $72 \mathrm{hs}$ & 7 \\
\hline NÃO REATOR & 132 & 50,2 & 156 & 59,3 & 176 & 66,9 & 84 & 31,9 & 86 & 32,7 & 93 & 35,4 \\
\hline REATOR FRACO & 106 & 40,3 & 95 & 36,1 & 87 & 33,1 & 155 & 58,9 & 149 & 56,7 & 142 & 54,0 \\
\hline REATOR FORTE & 25 & 9,5 & 12 & 4,6 & - & - & 24 & 9,2 & 28 & 10,6 & 28 & 10,6 \\
\hline TOTAL & 263 & 100,0 & 263 & 100,0 & 263 & 100,0 & 263 & 100,0 & 263 & 100,0 & 263 & 100,0 \\
\hline
\end{tabular}




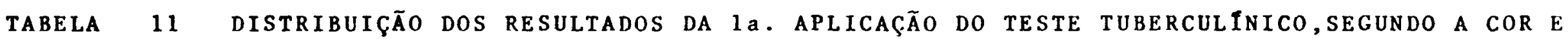

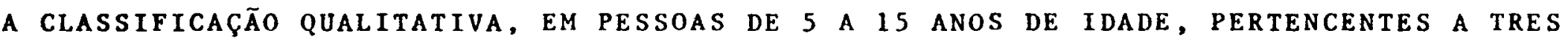
UNIDAdES da FEBEM. SÃo PAULO, 1977.

\begin{tabular}{|c|c|c|c|c|c|c|}
\hline \multirow[b]{2}{*}{ COR } & \multicolumn{2}{|c|}{ NÃO REATOR } & \multicolumn{2}{|c|}{ REATOR } & \multicolumn{2}{|c|}{ TOTAL } \\
\hline & NQ & $\%$ & NQ & $\pi$ & No & $\%$ \\
\hline BRANCA & 85 & 75,2 & 28 & 24,8 & 113 & 100,0 \\
\hline NÃO BRANCA & 91 & 60,7 & 59 & 39,3 & 150 & 100,0 \\
\hline TOTAL & 176 & 66,9 & 87 & 33,1 & 263 & 100,0 \\
\hline
\end{tabular}




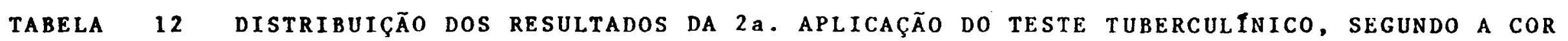

E A Classificação qualitativa, em pessoas de 5 a 15 anos de idade, pertencentes a TRES UNIDADES DA FEBEM. SÃO PAULO, 1977 .

\begin{tabular}{|c|c|c|c|c|c|c|}
\hline PPD & \multicolumn{2}{|c|}{ NÃO REATOR } & \multicolumn{2}{|c|}{ REATOR } & \multicolumn{2}{|c|}{ TOTAL } \\
\hline COR & No & $z$ & N9 & $\%$ & No & $z$ \\
\hline BRANCA & 43 & 38,0 & 70 & 62,0 & 113 & 100,0 \\
\hline NĀO BRANCA & 50 & 33,3 & 100 & 66,7 & 150 & 100,0 \\
\hline TOTAL & 93 & 35,4 & 170 & 64,6 & 263 & 100,0 \\
\hline
\end{tabular}


nas pessoas näo brancas.

A tabela 13, mostra os resultados das duas aplicaçōes do teste tuberculínico, em pessoas de cor jranca.

Das 85 pessoas não reatores na la. aplicação, 37 ou 43,5\% se mantiveram não reatores e 48 ou $56,5 \%$ passaram para reatores na $2 a$. aplicação. Dos 28 reatores na la. aplicação, 6 ou $21,4 \%$ passaram para não reatores e 22 ou $78,6 \%$ mantiveram-se reatores na $2 a$. aplicação.

A tabela 14, das pessoas não brancas, mostra que de 91 näo reatores na la. aplicação, 40 ou 43,9\% mantive ram-se não reatores e 51 ou $56,1 \%$ passaram para reatores na 2a. aplicação.

Houve maior percentual de reatores na la. aplica ção que se revelaram não reatores na $2 a$, nas pessoas bran cas com 21,4\% (tabela 13) em relação às pessoas não brancas $\operatorname{com} 16,9 \%$ (tabela 14).

Analisando os totais de reatores da 2 a. aplicação, as tabelas 13 e 14 mostram que houve maior percentual nas pessoas não orancas, com $66,7 \%$ em relação às pessoas brancas, $\operatorname{com} 61,9 \%$

A analise pelo teste $X^{2}$, confirma que a $2 a$ apli cação detectou maior número de reatores, independentemente da variável cor. 


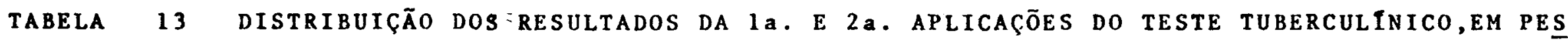

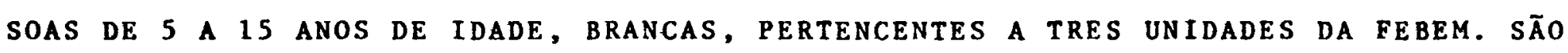
PAULO, 1977 .

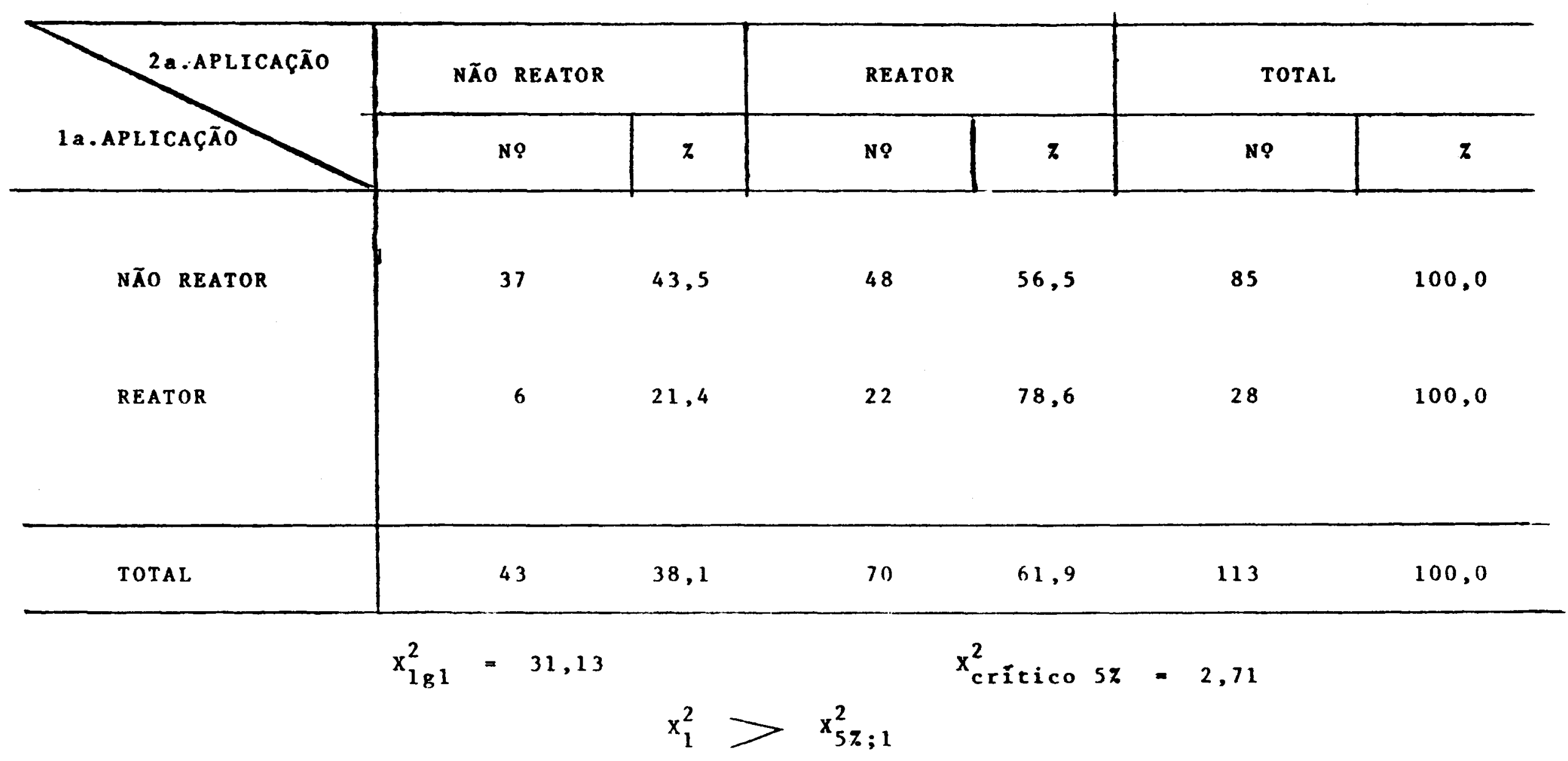




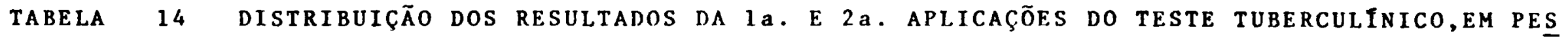
SOAS DE 5 A 15 ANOS DE IDADE, NÃO BRANCAS, PERTENCENTES A TRES UNIDAdes Da FEBEM. SÃo PAULO, 1977 .

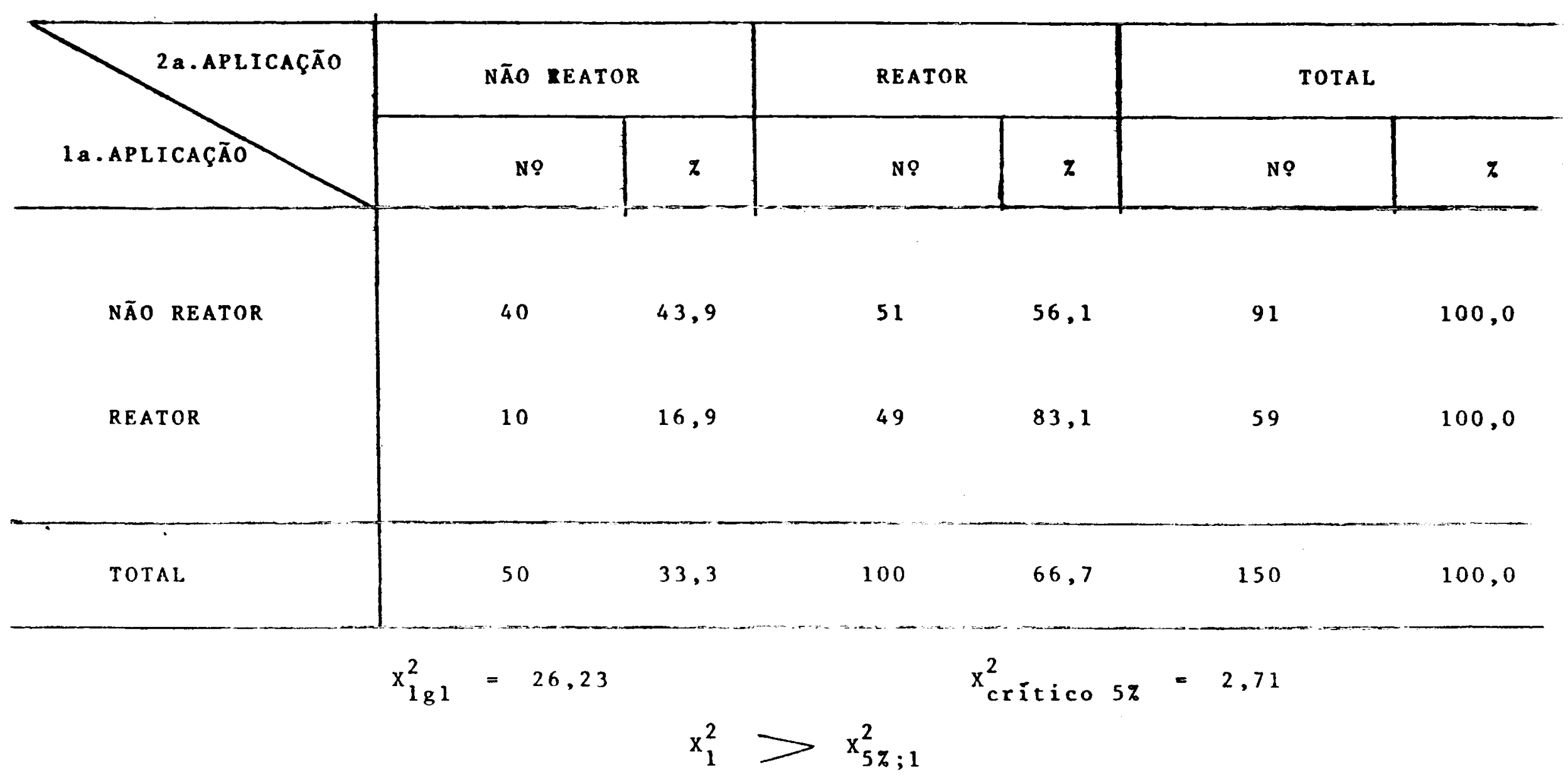


A tabela 15 é referente à la. aplicação do teste tuberculinico, em pessoas vacinadas e náo vacinadas anterior mente com BCG-id.

Os resultados mostram que de 99 pessoas vacina das, 51 ou $51,5 \%$ são não reatores e 48 ou $48,5 \%$ são reato res, e de 164 pessoas não vacinadas, 125 ou $76,2 \%$ são não rea tores, evidenciando contrariamente ao que se poderia esperar, que nos vacinados houve maior percentual de não reatores. Nos não vacinados o percentual de reatores é relativamente alto, de $23,8 \%$, considerando o grupo etário de 5 e 15 anos.

A tabela 16 é relativa à $2 a$. aplicação do teste tuberculínico, em pessoas vacinadas e não vacinadas anterior mente com BCG-id.

Os resultados demonstram que de 99 pessoas vacinadas, 22 ou $22,2 \%$ são não reatores e 77 ou $77,8 \%$ são reato res, e de 164 pessoas não vacinadas, 71 ou $43,3 \%$ se compor tam como não reatores e 93 ou $56,7 \%$ como reatores. Houve maior percentual de reatores entre os vacinados, provarelmente por serem pessoas que já contam com um substrato imunológico, embora não tenham respondido positivamente ao lo teste tuber culinico, como demonstrou a tabela 15.

Como evidencia BRŌLIo et al ${ }^{2}$ (1976) há um grande interesse de se conhecer o percentual de pessoas vacina das que se converteram em reatores. A 2 a. aplicação da prova tuberculinica pode representar um grande valor em saúde pública, por detectar maior número de reatores do que o obtido 


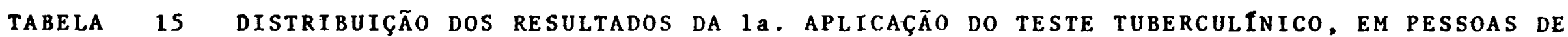
5 a 15 anos de idade, pertencentes a tres unidades da febem, vacinadas e não vaciNADAS ANTERIORMENTE COM BCG-id. SÃo PAULO, 1977.

\begin{tabular}{|c|c|c|c|c|c|c|}
\hline$\quad P P D$ & \multicolumn{2}{|c|}{ NĀO REATOR } & \multicolumn{2}{|c|}{ REATOR } & \multicolumn{2}{|c|}{ TOTAL } \\
\hline BCG-id & No & \% & N9 & 7 & NQ & $z$ \\
\hline NÃO VACINADAS & 125 & 76,2 & 39 & 23,8 & 164 & 100,0 \\
\hline TOTAL & 176 & 66,9 & 87 & 33,1 & 263 & 100,0 \\
\hline
\end{tabular}


TABEla 16 Distribuição dos Resultados da $2 a$. Aplicação do teste tuberculinico, em pesSoAs de 5 a 15 anos de idade, pertencentes a tres unidades da febem, vacinadas e não vaci_ NADAS ANTERIORMENTE COM BCG-id. SÃO PAULO, 1977.

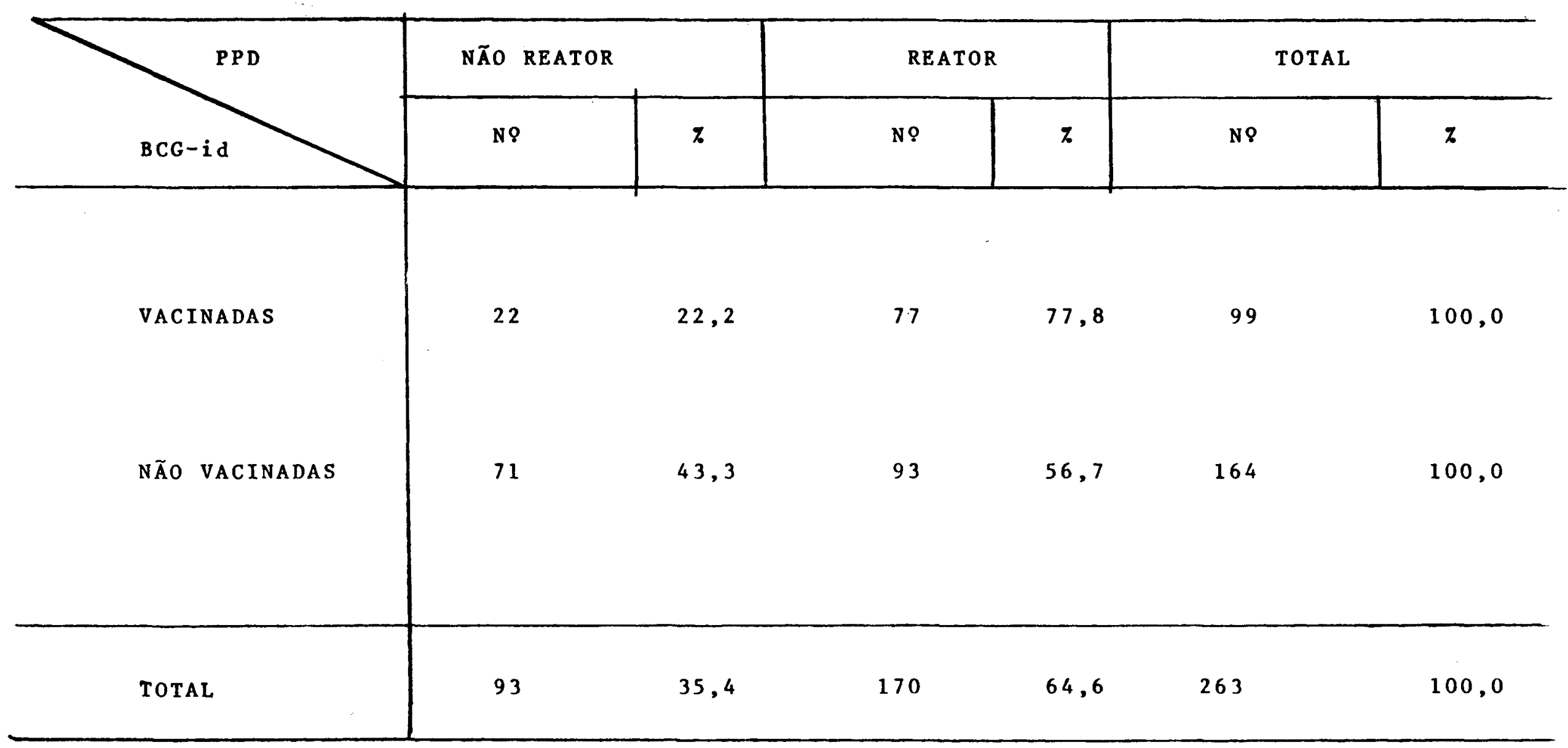


com uma única aplicação.

A tabela 17 mostra os resultados comparativos da 1a. e 2a. aplicações do teste tuberculínico, referente ao gru po de não vacinados anteriormente com BCG-id.

Fazendo análise da mesma, observa-se que de 125 pessoas não reatores na 1 a. aplicação, 60 ou $48,0 \%$ se nantiveram nessa mesma classificação e 65 ou $52,0 \%$ passaram para reatores r.a 2a. aplicação. E dos 39 reatores na la. aplica ção, 11 ou $28,2 \%$ tornaram-se não reatores e 28 ou $71,8 \%$ se mantiveram reatores na 2 a. aplicação.

Como foi citado no comentário da tabela 7 , o fato de reatores da la. aplicação, passarem para não reatores na 2a. aplicação, pode ser atribuído à diferença de leitura nas duas provas, ou à dessensibilização tecidual por tolerân cia imunológica.

Essa tabela demonstra que das 125 pessoas não reatores na 1a. aplicação, 65 ou $52,0 \%$ se converteram em rea tores, valorizando a $2 a$. aplicação do teste, na pesquisa de sensibilidade tuberculínica.

A tabela 18 refere-se aos resultados comparati vos das duas aplicações do teste tuberculínico, em pessoas anteriormente vacinadas com BCG-id.

A anälise mostra que de 51 pessoas não reatores na la. aplicação, 17 ou $33,3 \%$ se mantiveram não reatorese 34 
DISTRIBUIÇÃO DOS RESULTADOS DA 1 a. E 2a. APLICAÇÕES DO TESTE TUBERCULINICO,EM PES SOAS DE 5 A 15 ANOS DE IDADE, PERTENCENTES A TRES UNIDADES DA FEBEM, NÃO VACINADAS ANTERIORMENTE COM BCG-id. SÃO PAULO, 1977.

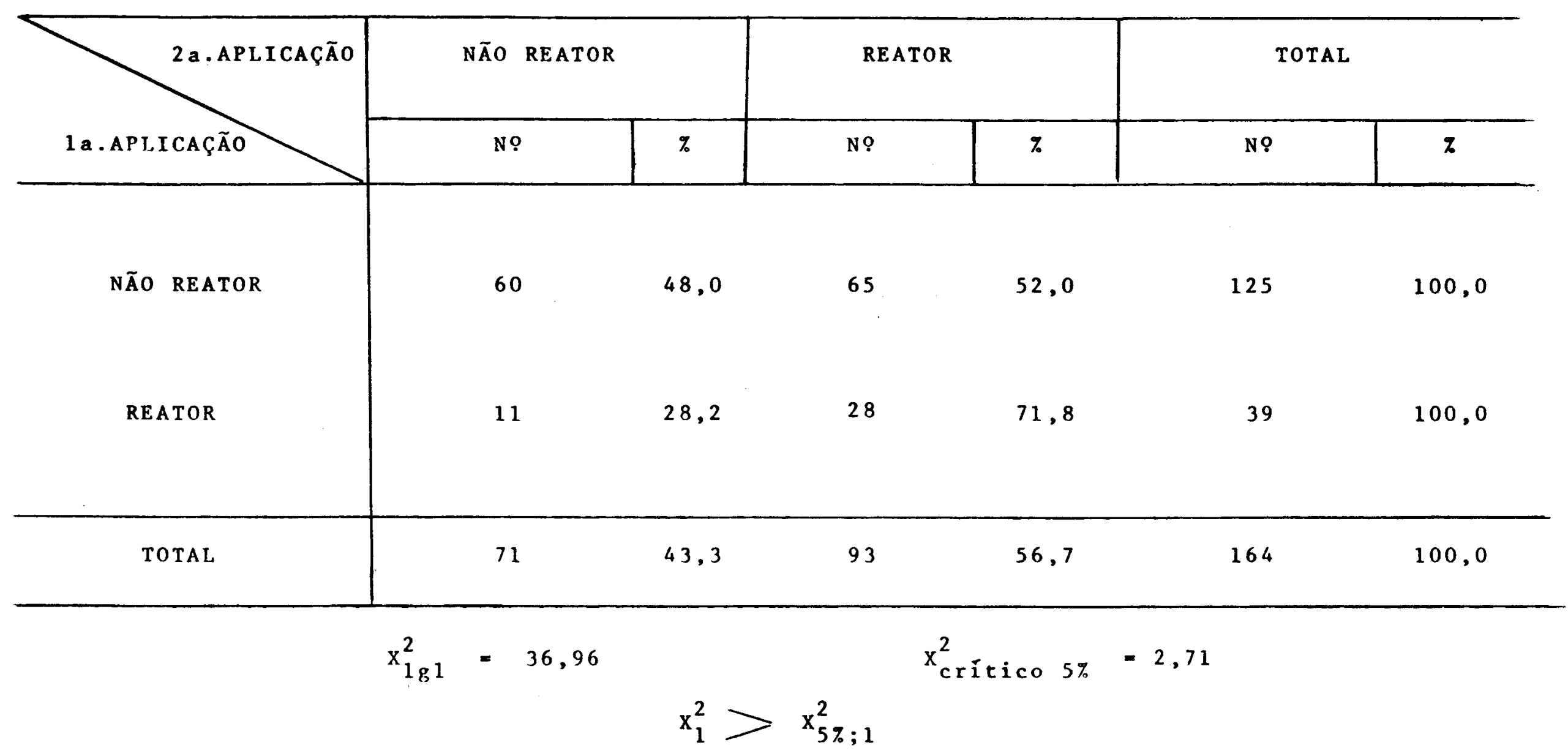




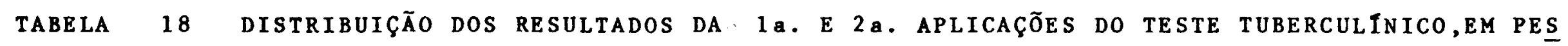

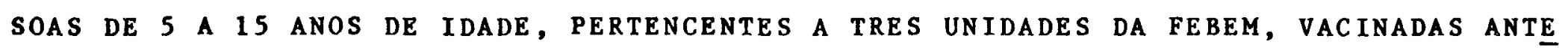
RIORMENTE COM BCG-id. SÃo PAULO, 1977.

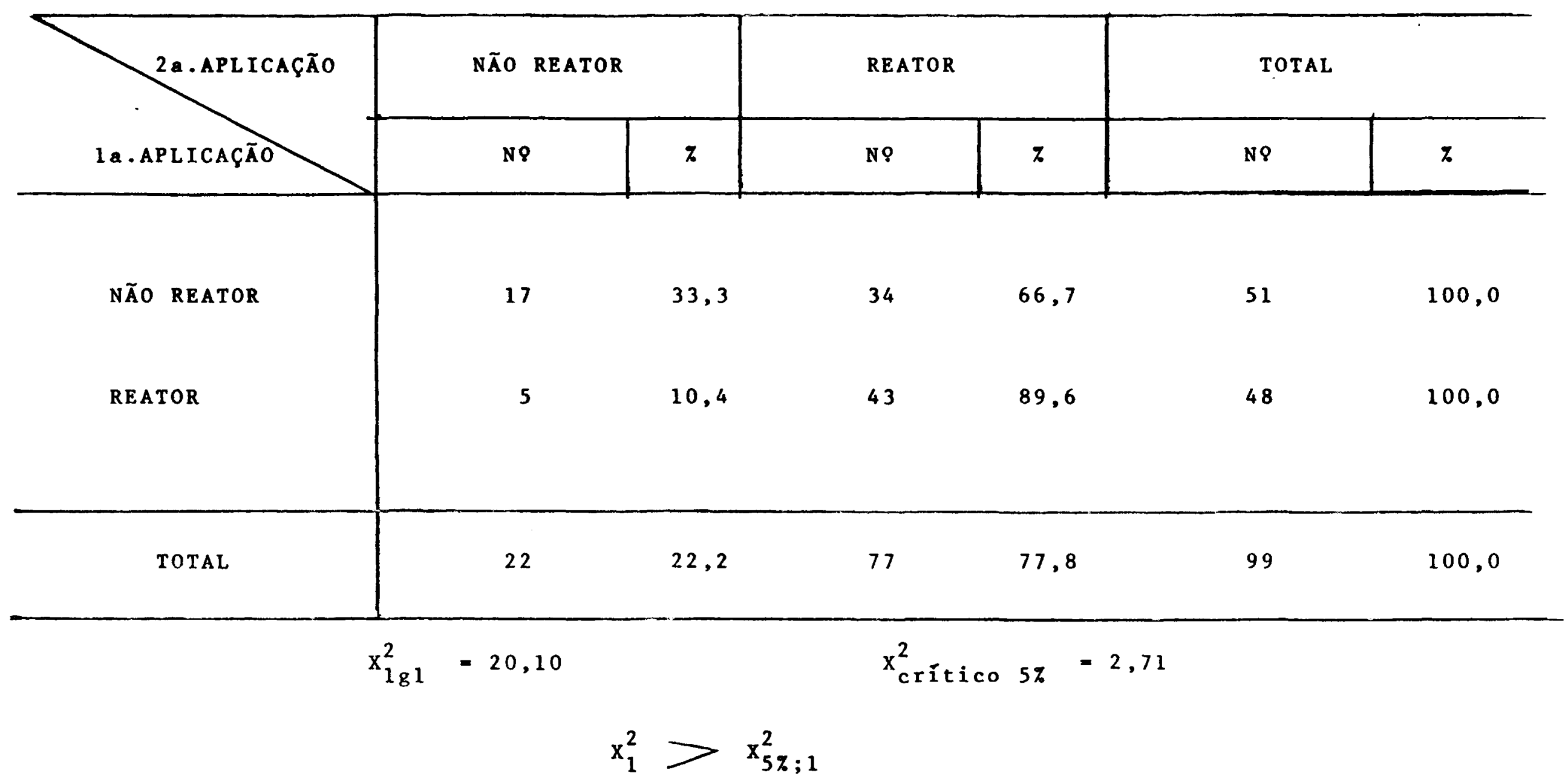


ou 66,7\% passaram para reatores. E do grupo de 48 reatores na 1a. aplicação, 5 ou $10,4 \%$ passaram para não reatores e 43 ou $89,6 \%$ continuaram reatores na 2 a. aplicação.

O estudo das tabelas 17 e 18 através do teste de $x^{2}$, evidencia que na $2 a$. aplicação do teste tuberculínico, hou ve diferença significante de reatores, independentemente de terem ou nào tomado BCG-id.

A tabela 19 mostra a distribuição de não reatores e reatores da 2 a. prova, segundo a aplicaçào no nesmo local e em local diferente (outro antebraço).

Das 133 pessoas que fizeramo teste no mesmo local, 30 ou $22,6 \%$ são näo reatores, 84 ou $63,1 \%$ são reatores fracos e 19 ou $14,3 \%$ são reatores fortes. E das 130 pessoas que fizeram o teste no outro antebraço, 63 ou $48,5 \%$ sāo não reatores, 58 ou $44,6 \%$ sào reatores fracos e 9 ou 6,$9 ;$ são rea tores fortes.

A análise estatistica dos resultados foi feita utilizando a técnica de comparação por contrastes de GoodMAN, para os tres grupos respectivamente, de nãc reatores, rea tores fracos e reatores fortes.

Para o grupo de não reatores, o teste evidenciou que houve uma diferença significante entre as proporções de resultados,para as pessoas que receberam a $2 a$. aplicação em local diferente. 
DISTRIBUIÇÃO DOS RESULTADOS DA $2 \mathrm{a}$. PROVA TUBERCULINICA, SEGUNDO O LOCAL DE APLICAÇĀQ, EM PESSOAS DE 5 A 15 ANOS DE IDADE, PERTENCENTES A TRES UNIDADES DA FEBEM. SÃO PAULO, 1977.

\begin{tabular}{|c|c|c|c|c|c|c|}
\hline \multirow[b]{2}{*}{ PPD } & \multicolumn{2}{|c|}{ MESMO } & \multicolumn{2}{|c|}{ DIFERENTE } & \multicolumn{2}{|c|}{ TOTAL } \\
\hline & No & $\%$ & NQ & $\%$ & N 9 & $\%$ \\
\hline NÃO REATOR & 30 & 22,6 & 63 & 48,5 & 93 & 35,3 \\
\hline REATOR FRACO & 84 & 63,1 & 58 & 44,6 & 142 & 54,0 \\
\hline REATOR FORTE & 19 & 14,3 & 9 & 6,9 & 28 & 10,6 \\
\hline TOTAL & 133 & 100,0 & 130 & 100,0 & 263 & 100,0 \\
\hline
\end{tabular}




$$
G_{1}^{2}=20,736 \quad x_{0,05 ; 2}^{2}=5,99
$$

Para o grupo de reatores fracos, pode-se verifi car a existência de evidência estatística, de maior propor çào dos mesmos, no grupo retestado no mesmo local.

$$
G_{2}^{2}=9,417 \quad x_{0,05 ; 2}^{2}=5,99
$$

Para o grupo de reatores fortes, embora o percentual seja maior nas pessoas testadas no mesmo local, o teste de GOODMAN mostra que não há evidéncia estatística, para afir mar que as proporções no mesmo local e em outro local, não são significativamente diferentes ao nível proposto.

$$
\begin{aligned}
& G_{3}^{2}=3,825 \quad x_{0,05 ; 2}^{2}=5,99 \\
& \mathrm{G}_{3}^{2}<\mathrm{x}_{0,05 ; 2}^{2}
\end{aligned}
$$

A tabela 19 mostra que no total de pessoas que fí zeram c teste no mesmo local, houve maior percentual de reato res, do que nos que fizeram em local diferente.

Este fato pode ser atribuído à mobilização para o local da 1a. aplicação, de maior nümero de linfócitos e que responderam prontamente à $2 a$. aplicação.

Em pesquisas realizadas pela OMS $^{15}$ (1955), DUBOCZY \& BROWN ${ }^{7}$ (1961), NARAIN et al ${ }^{13}$ (1966), foi verificado que a aplicação do teste tuberculínico no mesmo local, difere tan 
to em tamanho como no tipo de reação, em relação ao teste apli cado em lugar diferente.

$$
\text { BROLIO et al }{ }^{2} \text { (1976) citam que quando uma pessoa }
$$
apresenta hipersensibilidade tuberculínica hä muito tempo e faz o teste tuberculinico, o resultado pode ser negativo ou duvidoso, e a repetição do teste depois de pouco tempo pode dar maior reatividade, o que não deve ser interpretado como conver são, mas estímulo reacional induzido pela aplicação anterior.

Em outras palavras, a mesma afirmação encontra-se em SMITH et al 23 (1972) que referem que a maior reatividade no teste tuberculínico repetido pode ser atribuida ao efeito "booster", em pessoas previamente infectadas e com sensibilida de diminuida na primeira aplicação.

Os resultados do presente trabalho permitem verificar que a 2a. aplicação do teste tuberculínico, detectou maior número de reatores, em relação a la. aplicação, provave mente, devido a influência do efeito "booster".

Nas pessoas não reatores, vacinadas anteriormente com BCG-id, a 2a. aplicação tambēm revelou maior número de reatores, em relação ao lo teste.

Ficou evidenciado que a 2 a. aplicação do teste tuberculínico, é de grande valor em Saúde pública, por induzir uma maior reatividade tuberculínica em pessoas que já possuem um substrato imunológico e que não respondem positivamente à 
uma única aplicação do teste tuberculinico.

Relativamente às hipóteses formuladas na propo sição do presente trabalho, podemos afirmar que houve:

- confirmação da primeira hipótese, de que a re petição da prova tuberculínica com PPD,Rt-23,2UT após 72 ho ras oferece maior número de individuos reatores, quando com parada com a la. aplicação do teste tuberculínico;

- rejeição da segunda hipótese, mostrando diferença no tamanho da enduração nas leituras de 24,48 e 72 ho ras, tanto para a la. como da 2 a. aplicações;

- rejeif̧ão da terceira hipótese, mostrando dife rença nos resultados da 2 a. prova, em relação ao local de $\underline{a}$ plicação;

- aceitação da quarta hipótese, de que as pesso as vacinadas anteriormente com BCG-id e que säo näo reatores ao teste tuberculínico pós vacinal, respondem positivamente em maior percentual na $2 a$. aplicação. 
C O N 
A aplicação do teste tuberculinico com PPD, Rt-23, 2 UT, repetido depois de 72 horas, em pessoas de 5 a 15 anos de idade, pertencentes a tres Unidades da FEBEM, sugere as seguintes conclusões:

- Nas duas aplicações do teste tuberculínico pa dronizado/oms, leitura após 72 horas, detectou menor percen tual de reatores, comparadamente às respectivas leituras de 24 e 48 horas.

- As leituras da 2 a aplicação evidenciaram maior percentual de reatores em relação às respectivas leituras da 1a. aplicação.

- A repetição do teste tuberculínico depois de 72 horas, mostrou percentual mais elevado de reatores, em re lação ao primeiro teste, tanto em pessoas vacinadas como não vacinadas anteriormente pelo BCG-id.

- A repetição do teste no mesmo local, detectou maior percentual de reatores, em relação ao que foi aplicado em local diferente. 
$\begin{array}{lllllllllllllllllllllllll}R & E & F & E & R & E & N & C & I & A & S & B & I & B & L & I & O & G & R & \bar{A} & F & I & C & A & S\end{array}$ 
1. ARANTES, G.R. - Planejamento anti-tuberculose. Valor predictivo do teste tuberculínico negativo; Influência da triagem tuberculínica no valor predictivo da abreugrafia. São Paulo, 1974. (Tese de Doutoramento - Faculdade de Saúde Pública, USP).

2. BROLIO, R. et al. - Viabilidade da aplicação do teste tuberculínico com o Dermo-Jet. Rev. Saúde pübl.,S.Pau10, $10: 227-31,1976$.

3. CABOT, S.A.E. - The double intradermal tuberculin test delayed positive reactopms. Vet.Rec., 50:1233-34, 1938

4. CERTAIN, D.A. et a1. - Impregnação tuberculosa em menores de quatorze anos, detectada pela prova tuberculínica, en ¿uas àreas do município de são Paulo. Rev. Saúde pübl., S. Paulo, 5: $51 * 8,1971$.

5. DIVISÃo NACIONAL DE TUBERCUlose. Comissão Técnica - Pro va tuberculinica standard da OMS. Rio de Janeiro, 1967 .

6. Comissão Técnica - Pro va Tuberculínica em Saúde Püblica. 2a. recomendação. Rev. Serv. nac. Tuberc., $12: 219-30,1968$.

7. DUBOCZY, B.0. \& BROWN, B.T. - Local sensitization to tuber culin. Amer. Rev. resp. Dis., 84 (1):69, 1961 . 
8. FLEISS, J.L. - Statistical Methods for Rates and Proportions. New York, John Wiley, 1973. p. 72-89.

9. GlOVER, R.E. - The role of the tuberculin test in the fi ght against tuberculosis. XIV International Veteri nary Congress, 1939 .

10. GotTschalk, A.F. - Tuberculose: diagnósticc em bovinos pe la tuberculina. A enfermidade em bovinos é suinos de matadouro e como zoonose. Botucatu, 1971. (Tese de Doutoramento - Faculdade de Ciências Médicas e Biológicas de Botucatu, São Paulo).

11. GUEDES, E.A. - Estudo comparativo entre as provas de Man toux simples e dupla, 1975. (Trabalho não publicado).

12. Magaldi, C. - Aspectos epidemiológicos da tuberculose pul monar nos municípios de Botucatu, Conchas, Sãc Manuel e Avaré, Estado de São Paulo, Brasil, de 1963 a 1972. Rev. Saúde pübl., S. Paulo, 10:291-314, 1976.

13. NARAIN, R. et al. - Enhacing of tuberculin allergy by previous tuberculin testing. Bull. Wld. Hlth. Org., 34: 623,1966 .

14. - Interpretation of the repeat cubercu Iin test. Tubercle, Edinb., 49:92, 1968.

15. ORGANizAÇÃo MUNdial Da SAfide - Tuberculosis Fesearch offí 
ce - Repeated tuberculin tests in same site. Bull.Wld. H1th.Org., $12: 197,1955$.

16. ORGANIZAÇÃO MUNDIAL DA SAÚdE. Expert Committee on Tuberculosis. Report. Genebra, 1964. (W1d. H1th.Org.Techn. Rep.Ser., 290).

17. PAZ DE ALMEIdA, A. - Prevalência c̀a infecção tubercuolsa em escolares das capitais brasileiras. Relatório progressivo 2. Rev. Div. nac. Tuberc., 18:413-44, 1974 .

18. PRANDI, J.R. - Método de GOODMAN para comparação de proporçöes por contraste. São Paulo, Centro Nacional de Aperfeiçoamento de Pessoal para a Formação Profissional, 1973.

19. PRIESTLEY, F.W. - The Stormont tuberculin test: a statistical analysis. Vet. Rec., $58: 445,1946$.

20. RUFFino NETo, A. - Repetição da prova tuberculínica na mesma pessoa. HC. Med.CASE, 5 (4): 205-14, 1972 .

21 . - Dupla leitura das reações na prova tuber culinica. Rev. Div. nac. Tuberc., 18:33-37, 1974 .

22. SILVEIRA, J. \& MEDEIROS, S. - Aspectos atuais da alergia tú berculosa. Hosp. Rio de Janeiro, $\underline{62}: 425,1962$.

23. SMITH, D.T. et a1. - The problem of the "Boost" effect in tu berculin skin testing. Amer. Rev. resp. Dis., 106,1972. 
24. SPIEgEL, M.R. - Estatística. São Paulo. MacGraw Hill do Brasi1, 1971. p. 116-124, 131-144, 144-155. 